\title{
Investigating the performance of coupled WRF-ROMS simulations of Hurricane Irene (2011) in a regional climate modeling framework
}

\author{
P.A. Mooney ${ }^{\mathrm{a}, \mathrm{b}, *}$, F.J. Mulligan ${ }^{\mathrm{c}}$, C.L. Bruyère ${ }^{\mathrm{b}, \mathrm{d}}$, C.L. Parker ${ }^{\mathrm{e}, \mathrm{f}}$, D.O. Gill ${ }^{\mathrm{b}}$ \\ a Uni Research Climate, Bjerknes Centre for Climate Research, Bergen, Norway \\ ${ }^{\mathrm{b}}$ National Center for Atmospheric Research, Boulder, CO, USA \\ ${ }^{\mathrm{c}}$ Department of Experimental Physics, Maynooth University, Kildare, Ireland \\ d Environmental Sciences and Management, North-West University, South Africa \\ e Institute at Brown for Environment and Society, Brown University, Providence, RI, USA \\ ${ }^{\mathrm{f}}$ Department of Earth, Environmental and Planetary Sciences, Brown University, Providence, RI, USA
}

\section{A R T I C L E I N F O}

\section{Keywords:}

Tropical Cyclone

Hurricane

Irene

Atmosphere-ocean model coupling

Weather research and forecasting (WRF) model

Regional ocean modeling system (ROMS)

\begin{abstract}
A B S T R A C T
Hurricane Irene (2011) was a category 3 tropical storm that resulted in severe flooding, causing at least 40 deaths and more than $\$ 15$ billion in damaged property along the US northeastern seaboard (Avila and Cangialosi, 2011). This work analyzes the sensitivity of numerical simulations of this devastating storm to the physical parameterizations in the Weather Research and Forecasting (WRF) model and a coupled modeling framework (WRF and the Regional Ocean Modeling System). Simulations were conducted in two 16-member physics ensembles, each included two radiation schemes, two cumulus schemes, two microphysics schemes, and two planetary boundary layer schemes. The simulations were evaluated primarily on the accuracy of the simulated track and the intensity of the storm compared to observations over a period of 5 days centered on the storm's maximum intensity. Cumulus and planetary boundary layer parameterizations were the most influential physics schemes with radiation and microphysics having much smaller effects. The simulated track, intensity, translational speed, and rainfall rate were particularly sensitive to cumulus schemes given the differences in representation of shallow convection. Tracks and rainfall rates also showed sensitivity to the inclusion or exclusion of local effects in the parameterization of planetary boundary layer processes. Using a grid spacing of $12 \mathrm{~km}$, coupling an ocean model to WRF affected the storm track (with increased sensitivity to the cumulus scheme selected) and translational speed, but had very little effect on the rainfall rate or intensity of the storm. In terms of track accuracy, the optimal combination of physics parameterizations for WRF is not necessarily optimal for the coupled WRF-ROMS system.
\end{abstract}

\section{Introduction}

Tropical cyclones (TCs) present some of the greatest threats to life (Doocy et al., 2013) and damage to property (Blake et al., 2011). Consequently, the present and future climatology of TCs has been the subject of numerous modeling studies (Zhu and Zhang, 2006; Bender et al., 2010; Done et al., 2013; Doi et al., 2013; Strazzo et al., 2013; Park et al., 2014; Holland and Bruyère, 2014), many of which suggest that tropical storms will change in terms of frequency of occurrence, track, and intensity as a result of future climate change. While most climate models predict increases in intensity of the strongest storms, they also tend to predict an overall decrease in the total number of TCs (Walsh et al., 2016). Additionally, a number of studies have focused on analyzing systematic changes to TC characteristics such as intensity, wind speed, precipitation rate, translational speeds, and tracks (e.g. Kossin et al., 2016; Parker et al., 2018; Gutmann et al., 2018). These studies suggest that there could be significant changes to TC characteristics with climate change. However, the predictions are variable and sensitive to basins and TC cases. Furthermore, the reliability of these results remain a subject of debate due to the uncertainties in observed TC data and known deficiencies in the models used for predicting the future climatology of TCs. One of the greatest deficiencies in regional climate models for future predictions is a lack of coupling between atmosphere and ocean models (Chen et al., 2007).

Sea surface temperatures (SSTs) are a primary factor in cyclogenesis and a major contributor to the subsequent intensification of a TC (e.g. Bruyère et al., 2012). SSTs play an important role in the life cycle of a TC. However, TCs also have an important impact on the ocean surface.

\footnotetext{
* Corresponding author at: Uni Research Climate, Bjerknes Centre for Climate Research, Bergen, Norway.

E-mail address: priscilla.mooney@uni.no (P.A. Mooney).
} 
(a)

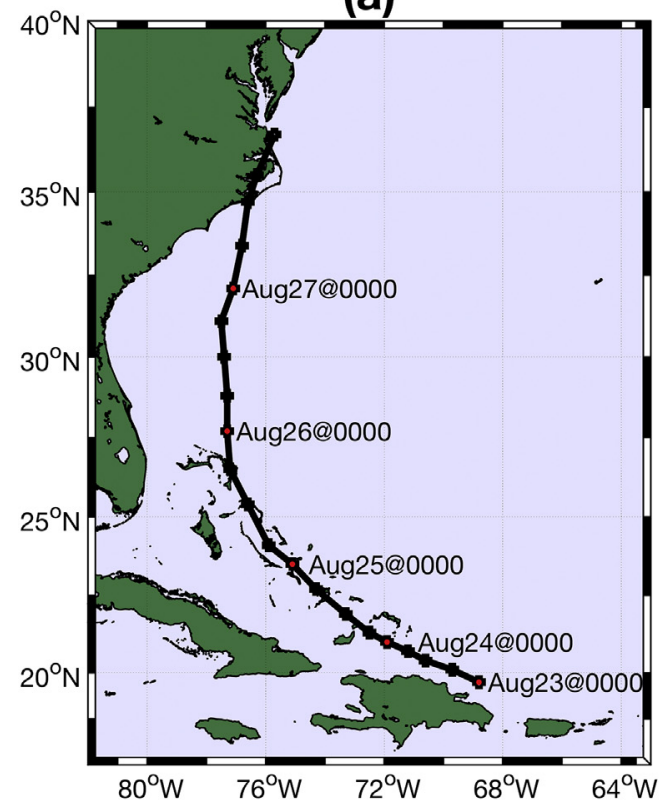

(b)

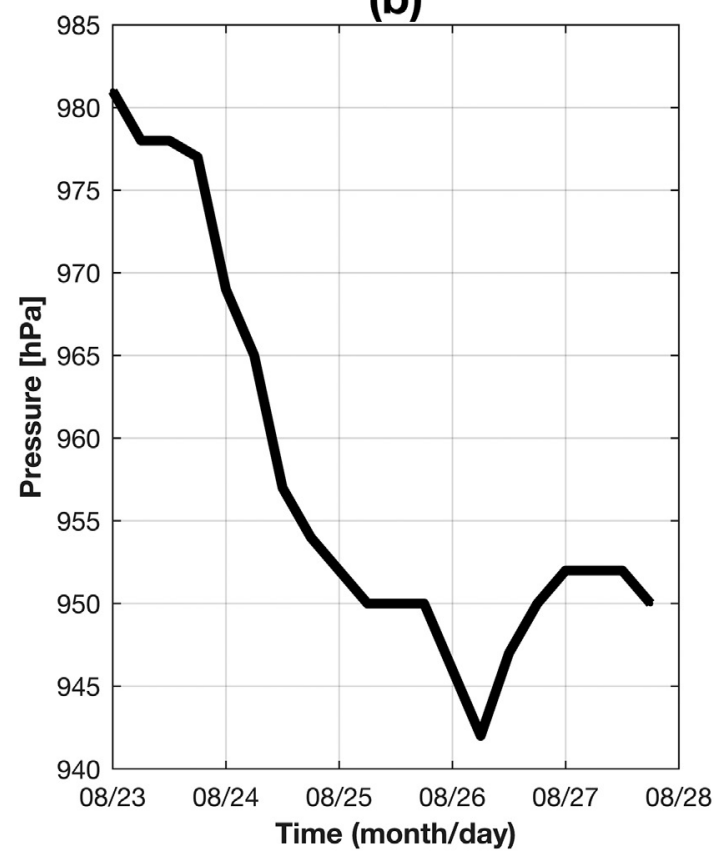

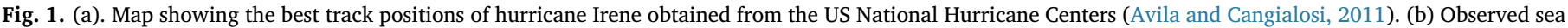
level pressure in hPa (hurricane intensity) for hurricane Irene.

TCs can cool the SST by up to $9^{\circ} \mathrm{C}$ (Lin et al., 2003) and leave behind cold wakes that can extend for hundreds of kilometers adjacent to the storm track (Dare and McBride, 2011). These SSTs often recover to their climatological values within 30 days (Dare and McBride, 2011), but can take up to 60 days (Hart et al., 2007). Lingering cold wakes can impact further seasonal TC activity due to interaction with later storms and possibly dampening intensification (Balaguru et al., 2014). This additional mixing may also be important on longer time scales through its impact on the large-scale, slowly varying ocean overturning circulation, and may affect the long-term climatology of TCs (Dare and McBride, 2011). Thus, the impact of individual TCs on the ocean surface can have an impact on subsequent TCs on seasonal to decadal time scales. Using coupled atmosphere-ocean models in regional climate studies of TCs is essential for capturing the dynamic interactions between the atmosphere and the ocean during and long after the passage of a TC.

While coupling has been used in numerical weather prediction of TCs (e.g. Bender and Ginis, 2000; Bender et al., 2007; Bao et al., 2000; Chen et al., 2007), it is in its infancy in regional climate modeling. The poor representation of atmosphere-ocean interactions is largely due to the high computational costs of running coupled simulations over long periods of time covering very large domains, e.g., the North Atlantic basin. Prior to application of a coupled atmosphere-ocean modeling system to regional climate studies of TCs, it is necessary to understand the strengths and limitations of the coupled system so that accurate conclusions can be drawn from such studies. Precursor studies are also essential for identifying optimal configurations of the regional climate model. However, carrying out multiple, long-term, coupled atmosphere-ocean simulations for the purpose of identifying optimal configurations involving multiple models is computationally intensive and expensive. Several authors (e.g. Jankov et al., 2005; Evans et al., 2012) have addressed this difficulty of computational expense by investigating one or more short-term, extreme events with multiple simulations using different model configurations. This experimental methodology produces a more comprehensive evaluation of different model configurations while minimizing computational time.

This study applies the event-based approach to investigate the suitability of a coupled WRF-ROMS modeling system to regional climate studies of TCs. Thirty-two simulations of TC Irene (2011) have been produced; the first sixteen simulations use only the WRF model while the other sixteen use the coupled WRF-ROMS system.

TC Irene was chosen as the test case because the air-sea interactions were important for forecasting the intensity of Irene. Details of TC Irene are provided in the following section. Section 3 describes the regional climate model and coupled model setup, initialization and forcing data together with the observed data used for model evaluation. Section 4 presents the results while Sections 5 and 6 summarize the results and describe our conclusions. This study adds to the current understanding of the strengths and limitations of ocean coupling for simulating the climatology of TCs in the North Atlantic with a coupled WRF-ROMS modeling system. Additionally, this work demonstrates how coupling interacts with the parameterization of atmospheric processes in WRF and how this can have disparate effects on simulation outcome.

\section{Case study}

Hurricane Irene has been the subject of some previous studies (Mooney et al., 2016; Yablonsky et al., 2015; Klausmann, 2014) because of the scale of its impact on people and property. While its maximum intensity did not exceed category 3 on the Saffir-Simpson scale, it was a very large storm. Hurricane force winds extended nearly $150 \mathrm{~km}$ from the center, which had major environmental and societal impacts. Irene is an example of a TC whose track was forecast with good accuracy by the US National Hurricane Center, but whose intensity did not reach forecast values, primarily because the forecast model underestimated the hurricane-induced upper-ocean cooling (Glenn et al., 2016). In this study, Irene is simulated from the 23rd to the 28th of August 2011. During this period, Irene intensified from approximately $980 \mathrm{hPa}$ to its maximum intensity of approximately $940 \mathrm{hPa}$. Fig. 1(a) and (b) show the best observed track and pressure for this time, which were obtained from the US National Hurricane Center's reports (Avila and Cangialosi, 2011). By the 23rd of August 2011 Irene had reached hurricane status, and on the 24th of August 2011 it strengthened into a category 3 hurricane when it was between Mayaguana and Grand Inagua in the Bahamas. Irene weakened slightly as it moved over Long Island, Bahamas on the 25th of August at 0000 UTC and turned northnorthwest and eventually north around 0600 UTC. This change in 
direction was associated with the eastward shift of the subtropical high in the North Atlantic (Avila and Cangialosi, 2011). Irene weakened as it continued northward and made landfall near Cape Lookout, North Carolina on the 27th of August at 1200 UTC.

\section{Experimental setup}

\subsection{Observed data}

Best track and sea-level pressure for TC Irene were obtained from the US National Hurricane Center's reports (Avila and Cangialosi, 2011). Modeled sea surface temperatures (SSTs) were compared with the Operational Sea Surface Temperature and Sea Ice Analysis (OSTIA; Stark et al., 2007) obtained from http://podaac.jpl.nasa.gov/dataset/ UKMO-L4HRfnd-GLOB-OSTIA. OSTIA data used in this study is a Group for High Resolution Sea Surface Temperature Level 4 SST analysis produced daily on a global $0.054^{\circ}$ grid by the UK Met Office using optimal interpolation. Observed precipitation data for the Tropical Rainfall Measuring Mission (TRMM) was obtained from https://disc. gsfc.nasa.gov/datasets/TRMM_3B42_7/summary on $0.25^{\circ}$ grid.

\subsection{COAWST coupling}

The coupled modeling system used in this study is the Coupled Ocean-Atmosphere-Wave-Sediment Transport (COAWST; Warner et al., 2010) modeling system, which was developed at the US Geological Survey in Woods Hole. COAWST uses the Model Coupling Toolkit (MCT; Larson et al., 2004) to couple together the Weather Research and Forecasting (WRF; Skamarock et al., 2008) model, the Regional Ocean Modeling System (ROMS; Shchepetkin and McWilliams, 2005), the Simulating WAves Nearshore (SWAN; Booij et al., 1999) model and the Community Sediment Transport Model (CSTM, Warner et al., 2008). Each component of the COAWST system can be switched on or off at compile time and the entire system is parallelized. As the focus of this study is on ocean coupling, only WRF and ROMS are activated and both the sediment transport model and SWAN are switched off. MCT is the master controller of the COAWST system and the flexible design of the system allows the user to determine when the models exchange data.

At each exchange interval, WRF receives values for SSTs from ROMS. To ensure consistency between the two models, WRF provides ROMS with values for the sensible heat flux, latent heat flux, net shortwave radiation flux at ground surface and downward longwave radiation flux at the ground surface. ROMS also receives values for sea level pressure and wind stress from WRF. An investigation on the sensitivity of the simulation results to the exchange interval (results not shown) showed that simulations with exchanges at intervals of $10 \mathrm{~min}$ were not significantly different from those with $60 \mathrm{~min}$. However, larger intervals of $6 \mathrm{~h}$ or more degraded the simulation. An exchange interval of $60 \mathrm{~min}$ was therefore selected to optimize computational performance without degrading the simulations.

\subsection{Model domains and details of initializations}

The model domains used in this study are shown in Fig. 2. WRF uses two domains with the outer domain having a grid spacing of $36 \mathrm{~km}$ and the nested inner domain has a grid spacing of $12 \mathrm{~km}$. Although previous studies such as Davis et al. (2010) have shown that maximum winds, rapid intensification and wind radii are predicted more accurately with higher resolutions $(1.33 \mathrm{~km})$, this study uses a coarser grid spacing since it is focused on evaluating the ability of WRF-ROMS to simulate TCs in regional climate simulations which typically have grid spacings of 10-15 km (Jacob et al., 2014; Kotlarski et al., 2014). Simulations of Hurricane Irene cover the period from 0000 UTC on the 23rd of August 2011 to 0000 UTC on the 28th of August 2011 to cover the main intensification period and landfall of the TC.

Initial conditions and boundary conditions provided to WRF at six hourly intervals were derived from the interim European Centre for Medium Range Weather Forecasts (ECMWF) Re-analysis (ERA-Interim; Dee et al., 2011). ERA-Interim is the most widely used reanalysis for regional climate modeling, and studies have shown that it provides the best representation of certain aspects of the climate system (Mooney et al., 2011; Troy and Wood, 2009). SSTs in ERA-Interim are prescribed boundary conditions and obtained from the Operational Sea Surface Temperature and Sea-Ice Analysis (Dee et al., 2011). A study by Parker et al. (2017) has shown that SSTs from ERA-Interim have a 30-h lag compared to SSTs from OSTIA. This lag is corrected in the ERA-Interim SSTs used in this study.

Both WRF domains have 51 full eta levels with a pressure top of $10 \mathrm{hPa}$. The outer $36 \mathrm{~km}$ domain has 340 (nominally east-west) by 260 (nominally north-south) grid points while the inner $12 \mathrm{~km}$ domain has $802 \times 511$ grid points. Since the aim of this study is to identify the strengths and limitations of a regional climate model in simulating TCs, WRF is configured here without such options as data assimilation, digital filter initialization or cycling, and the finest resolution grid spacing used is $12 \mathrm{~km}$. The physical parameterizations used in this study vary between the experiments and are described in detail in section 3.4.

ROMS uses a single domain (see Fig. 2) with a grid spacing of $12 \mathrm{~km}$ that covers the same area as the WRF outer domain. Initial conditions and values at the open boundaries were provided to ROMS from the global HYbrid Coordinate Ocean Model (HYCOM) with Naval Research Lab (NRL) Coupled Ocean Data Assimilation (HYCOM/NCODA; Cummings, 2005). Previous studies (e.g. Winterbottom et al., 2012) have shown that the ocean mixed layer response to inconsistent atmospheric forcing leads to an oscillation resulting from an imbalance at the air-sea interface. To address this imbalance, all coupled simulations in this study use a 10-day spin-up period for ROMS. The ROMS model uses 30 stretched terrain-following vertical levels with a finer grid near the surface and bottom in order to better resolve the ocean boundary layers. HYCOM/NCODA tracer (temperature and salinity) and threedimensional velocity fields are provided to ROMS using Orlanski-type radiation conditions in conjunction with relaxation (timescale of 10 days on outflow and 0.5 days on inflow). Boundary values for the free-surface and depth-averaged velocity were obtained from HYCOM/ NCODA using the Flather (1976) method. Vertical turbulent mixing and specification of the quadratic drag formulation for the bottom friction was calculated using the Generic Length Scale vertical mixing scheme (Warner et al., 2005). Other model parameters for ROMS are shown in Table 1.

\subsection{WRF physics parameterizations}

Parameterization schemes in the WRF model can be broadly categorized into (1) land surface model, (2) microphysics, (3) longwave radiation, (4) shortwave radiation, (5) convection schemes and (6) planetary boundary layer (PBL). Within each of these categories there exist numerous parameterization schemes, some of which are applicable to climate modeling while others are better suited to numerical weather prediction. The parameterization scheme combinations examined in this study are shown in Table 2. Land surface models are not investigated here, as they do not directly interact with the ocean surface, which is the focus of this study.

We examined the WRF Single Moment six-class (WSM6) microphysics scheme (Hong and Lim, 2006), WRF Double Moment six class (WDM6) scheme (Lim and Hong, 2010), Community Atmosphere Model (CAM) radiation (Collins et al., 2004), Rapid Radiation Transfer Model (RRTMG; Mlawer et al., 1997 and Iacono et al., 2008), Yonsei University (YSU; Hong et al., 2006) PBL scheme, Mellor-Yamada Nakanishi and Niino level 2.5 (MYNN) PBL scheme (Mellor and Yamada, 1982; Nakanishi and Niino, 2006; 2009), Kain-Fritsch (KF; Kain and Fritsch, 1990; Kain, 2004) and Tiedtke (Tk; Tiedtke, 1989; Zhang et al., 2011) convective schemes. All simulations use the Noah Land Surface Model (Ek and Mahrt, 1991). These parameterization schemes were chosen 


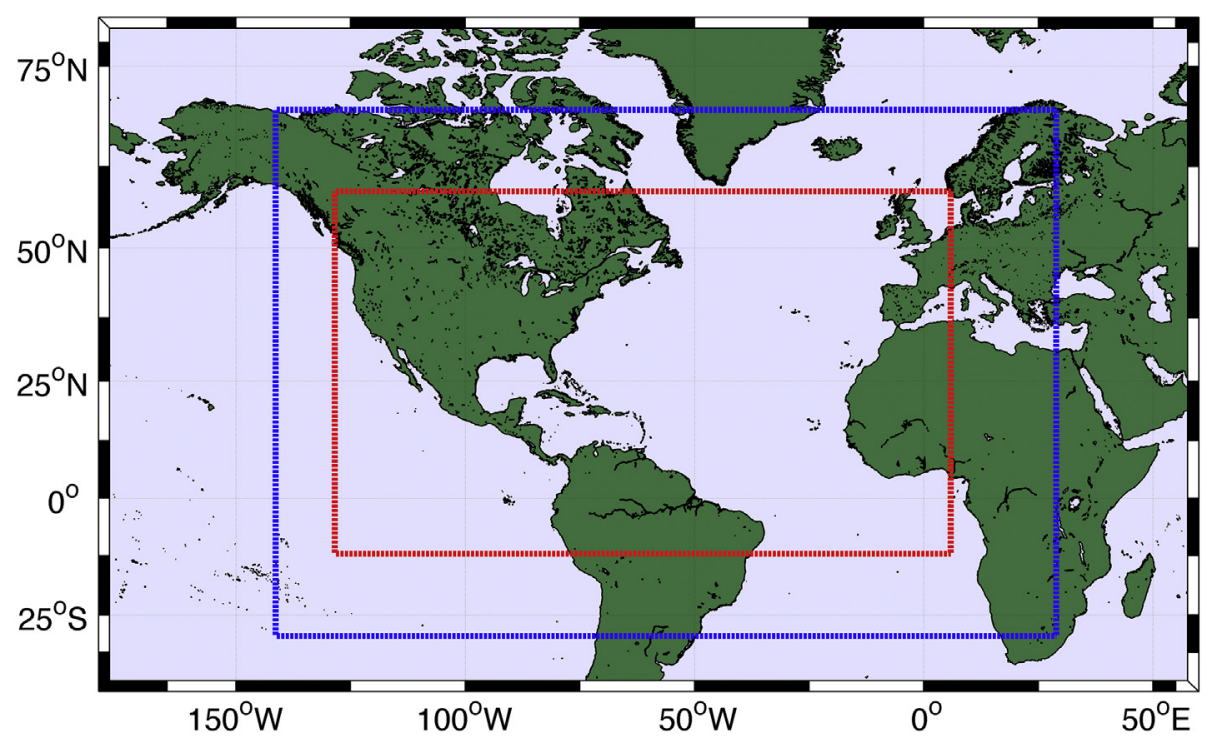

Fig. 2. Map showing the outer domain (blue) used by both WRF and ROMS and inner (red) domain used by WRF for all simulations. (For interpretation of the references to colour in this figure legend, the reader is referred to the web version of this article.)

Table 1

Basic model parameters for ROMS.

\begin{tabular}{lll}
\hline$d x$ & $12 \mathrm{~km}$ & Resolution zonal direction \\
$d y$ & $12 \mathrm{~km}$ & Resolution meridonal direction \\
$L$ & 1015 & Number of I-direction interior rho-points \\
$M$ & 775 & Number of J-direction interior rho-points \\
$N$ & 30 & Number of sigma coordinate levels \\
$h_{\max }$ & $5000 \mathrm{~m}$ & Maximum depth of computational domain \\
$h_{\min }$ & $50 \mathrm{~m}$ & Minimum depth of computational domain \\
$\theta_{s}$ & 5 & Sigma coordinate stretching factor \\
$\theta_{b}$ & 0.4 & Sigma coordinate bottom stretching factor \\
$d t$ (baroclinic) & $30 \mathrm{~s}$ & Baroclinic time step \\
$d t$ (barotropic) & $1 \mathrm{~s}$ & Barotropic time step \\
outflow & 10 days & \\
inflow & 0.5 days & \\
\hline
\end{tabular}

Table 2

Physical parameterization schemes used in both the WRF-only and WRF-ROMS simulations. RRTMG: Rapid Radiative Transfer Model (RRTM); CAM: Community Atmosphere Model (CAM). WRF Single Moment 6-class scheme (WSM6); WDM6: WRF Double Moment 6-class scheme (WDM6). Ys: Yonsei University (YSU); My: Mellor-Yamada Nakanishi and Niino Level 2.5 (MYNN). Kain Fritsch (KF) and Tiedtke (Tk) convective schemes.

\begin{tabular}{|c|c|c|c|c|c|}
\hline & & Radiation & Micro-physics & PBL & Cumulus \\
\hline 1 & Ca_S6_Ys_KF & CAM & WSM6 & YSU & Kain-Fritsch \\
\hline 2 & Ca_S6_Ys_Tk & CAM & WSM6 & YSU & Tiedtke \\
\hline 3 & Ca_S6_My_KF & CAM & WSM6 & MYNN & Kain-Fritsch \\
\hline 4 & Ca_S6_My_Tk & CAM & WSM6 & MYNN & Tiedtke \\
\hline 5 & Ca_D6_Ys_KF & CAM & WDM6 & YSU & Kain-Fritsch \\
\hline 6 & Ca_D6_Ys_Tk & CAM & WDM6 & YSU & Tiedtke \\
\hline 7 & Ca_D6_My_KF & CAM & WDM6 & MYNN & Kain-Fritsch \\
\hline 8 & Ca_D6_My_Tk & CAM & WDM6 & MYNN & Tiedtke \\
\hline 9 & $R R \_S \sigma_{-} Y S_{-} K F$ & RRTMG & WSM6 & YSU & Kain-Fritsch \\
\hline 10 & $R R \_S 6 \_Y s \_T k$ & RRTMG & WSM6 & YSU & Tiedtke \\
\hline 11 & $R R S 6 \sigma_{-} M y_{-} K F$ & RRTMG & WSM6 & MYNN & Kain-Fritsch \\
\hline 12 & $R R \_S 6_{-} M y_{-} T k$ & RRTMG & WSM6 & MYNN & Tiedtke \\
\hline 13 & $R R \_D 6_{-} Y s_{-} K F$ & RRTMG & WDM6 & YSU & Kain-Fritsch \\
\hline 14 & $R R \_D 6 \_Y s_{-} T k$ & RRTMG & WDM6 & YSU & Tiedtke \\
\hline 15 & $R R \_D 6 \_M y_{-} K F$ & RRTMG & WDM6 & MYNN & Kain-Fritsch \\
\hline 16 & $R R \_D 6 \_M y_{-} T k$ & RRTMG & WDM6 & MYNN & Tiedtke \\
\hline
\end{tabular}

because they are the most widely used schemes available in WRF for regional climate modeling. The contrasting characteristics of the schemes enables comparison between different assumptions and methods used within the different parameterization categories. For example, YSU and MYNN were chosen because one is a "local" PBL scheme and the other is a "non-local" scheme. Similiarly, the KainFritsch and Tiedtke cumulus schemes were chosen because one has more active shallow convection over ocean surfaces than the other. All of the combinations simulated with both the WRF model and the WRFROMS coupled system are shown in Table 2 along with the names for each simulation. The names of the simulations are derived from the parameterization schemes used so that the name is informative regarding the physics combinations. For example, the simulation $\mathrm{Ca}_{-}-$ S6_Ys_KF uses the CAM radiation schemes, the WSM6 microphysics scheme, the YSU PBL scheme and the KF cumulus scheme. The sensitivity of the model setup to these schemes is assessed by examining primarily their ability to reproduce the storm track and intensity of Hurricane Irene (2011), but also the translational speed (forward speed of the storm) and the rainfall along the track of the storm.

\section{Results and discussion}

\subsection{TC track}

Fig. 3(a)-(d) show the best-observed track, modeled tracks, and their root-mean-squared errors (RMSE) for Irene using both WRF (Fig. 3(a) and (c)) and WRF-ROMS (Fig. 3(b) and (d)). The modeled tracks are determined by locating the minimum in the mean sea level pressure at six-hour intervals within a radius of $300 \mathrm{~km}$ of the corresponding point at the previous interval. Fig. 3(a) and (b) show that the simulated tracks are generally in good agreement with the best-observed track for both model configurations. RMSE track values (shown in Fig. 3(c) and (d)) indicate that the tracks simulated by WRF are closer to the observed track than those from WRF-ROMS.

The simulated tracks of Irene show three distinct groups, which separate in terms of cumulus and PBL schemes: 1) KF and YSU, 2) KF and MYNN, and 3) Tk and either YSU or MYNN. In the WRF-only simulations, the best-simulated tracks, as indicated by the RMSE values, are those simulations with the KF cumulus scheme and the YSU PBL scheme (blue lines in Fig. 3(a)). The poorest simulated tracks are those using the KF cumulus scheme and the MYNN PBL scheme (red lines in Fig. 3(a)). The remaining simulations, all of which use the Tk cumulus scheme have RMSE values bounded by the previous two groups. Within the Tk group, most simulations using MYNN (purple lines in Fig. 3(a)) marginally outperform those using the YSU PBL scheme (green lines in Fig. 3(a)). 
(a)

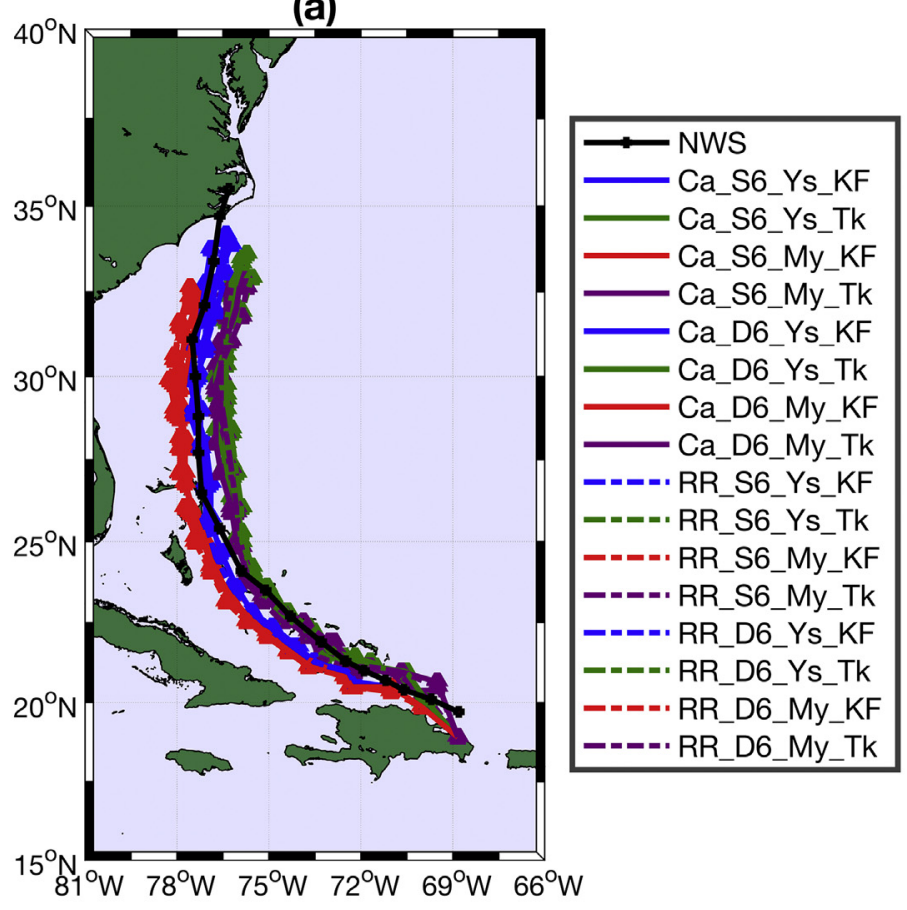

(b)

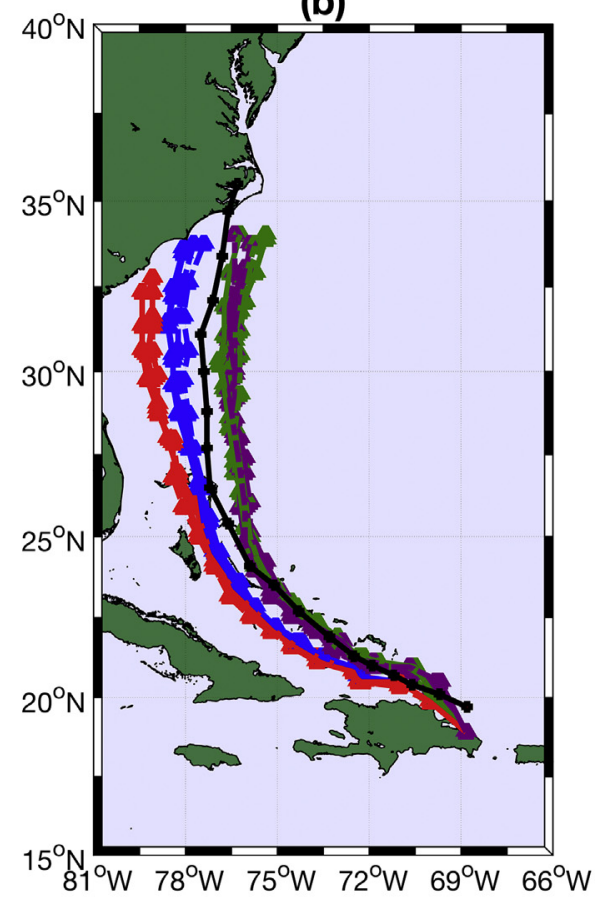

(c)

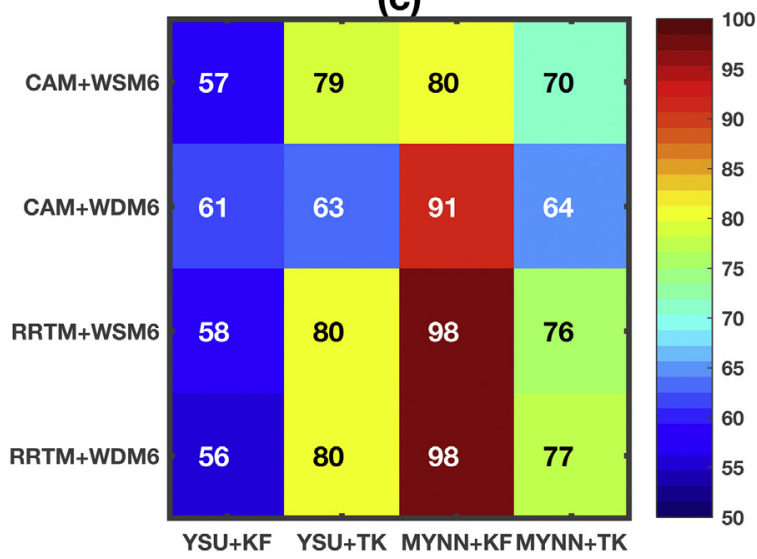

(d)

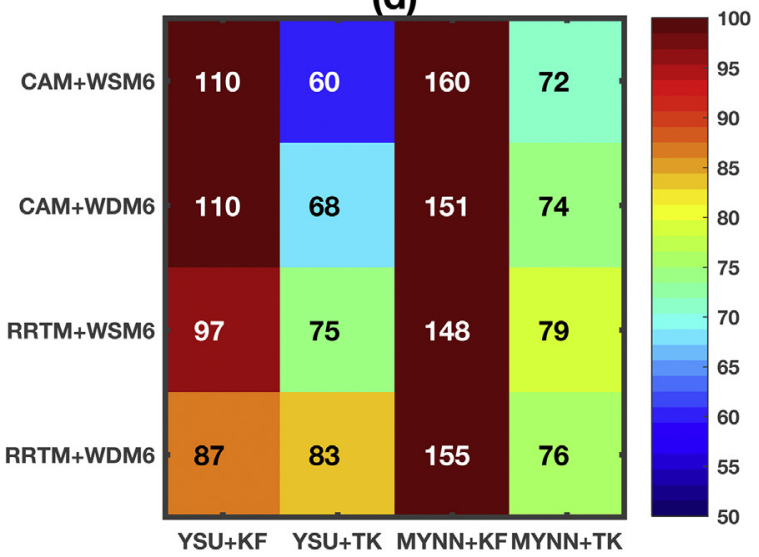

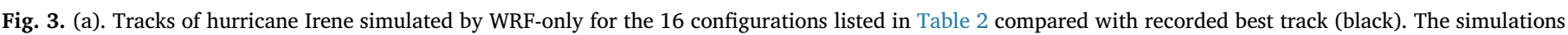

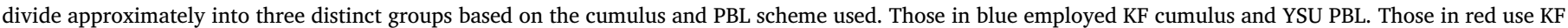

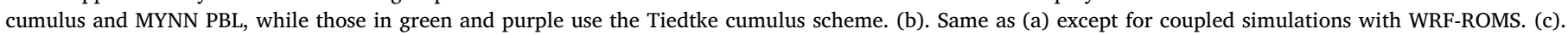

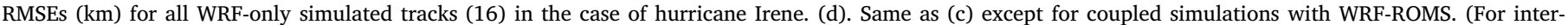
pretation of the references to colour in this figure legend, the reader is referred to the web version of this article.)

While the above groupings are also clearly evident in the WRFROMS simulations, the performance of the different combinations is altered by coupling the ocean model ROMS to WRF. RMSE values (Fig. 3(d)) show that the Tk group, which now outperforms the other two groups, is largely unaffected by the coupling. However, the RMSE values for both KF groups have increased by $>50 \%$. Consequently, the KF-YSU combinations now perform worse than the Tk group; and the KF-MYNN group, still the poorest performing group, has deteriorated substantially. Therefore, simulations with Tk produce tracks that are largely insensitive to coupling while simulations with KF yield tracks that are sensitive to coupling the WRF model to ROMS.

\subsubsection{North Atlantic subtropical high}

As mentioned in Section 2.1, the observed trajectory of Irene was strongly associated with the subtropical high in the North Atlantic. Thus, a difference in the location of the subtropical high between simulations presents a possible explanation for the variations in the simulated track. Fig. 4 shows contour plots of the geopotential height at $500 \mathrm{hPa}$ averaged over the 5-day period for a selection of simulations. Fig. 4(a) shows the values for a WRF-only simulation that uses KF (Ca_S6_Ys_KF; see Table 2 for details on simulation name) in red and a corresponding WRF-only simulation that uses Tk (Ca_S6_Ys_Tk) overlain in blue. The contours in the North Atlantic show clearly that the subtropical high in the KF (Ca_S6_Ys_KF) simulation extends further west than in the Tk (Ca_S6_Ys_Tk) simulation. Consequently, the TC in the Tk simulation turns northwards earlier than the TC in the corresponding KF simulation which can continue westward for a slightly longer period of time. As a result, the TC track in the KF simulation is further westward than the track in the Tk simulation. This difference between the KF and Tk simulations in the $500 \mathrm{hPa}$ geopotential heights was also evident in the remaining simulations (not shown).

Importantly, the results demonstrate that the PBL schemes influence 
(a)

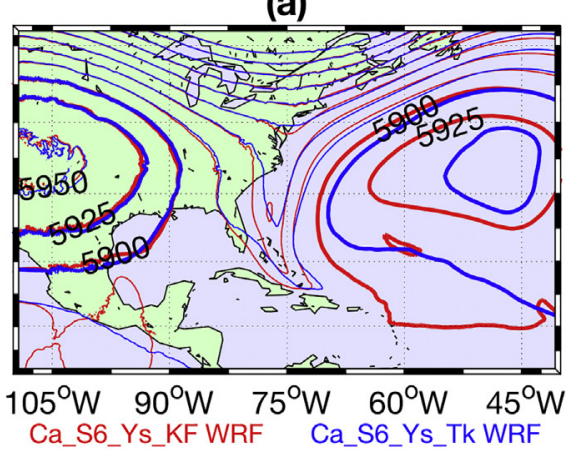

(b)

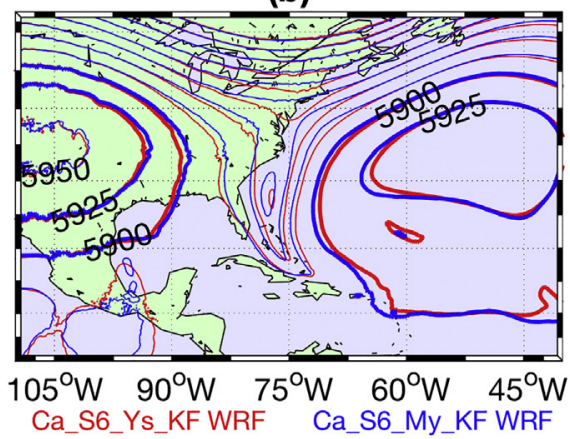

(d)

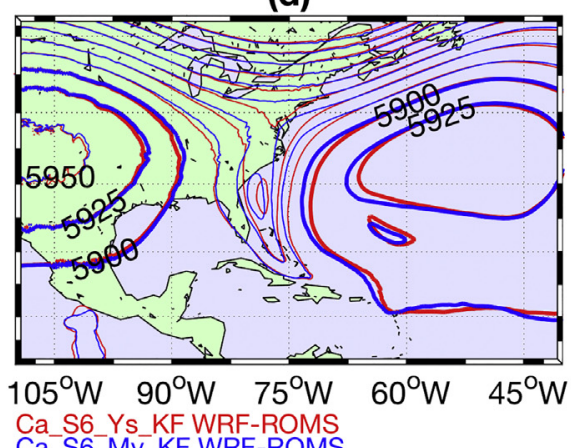

Ca_S6_My_KF WRF-ROMS

(f)

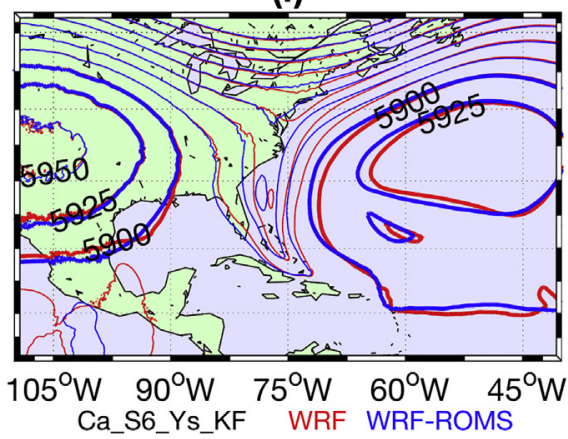

(c)

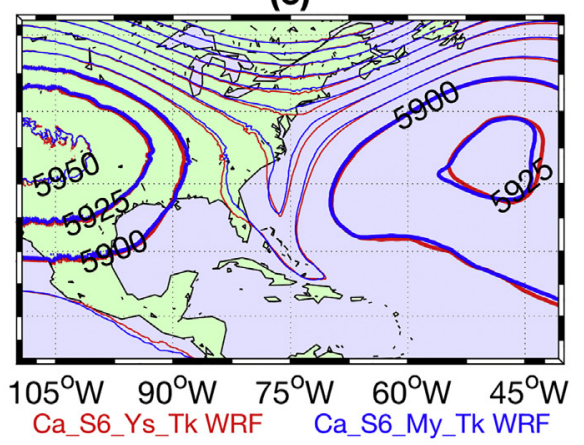

(e)

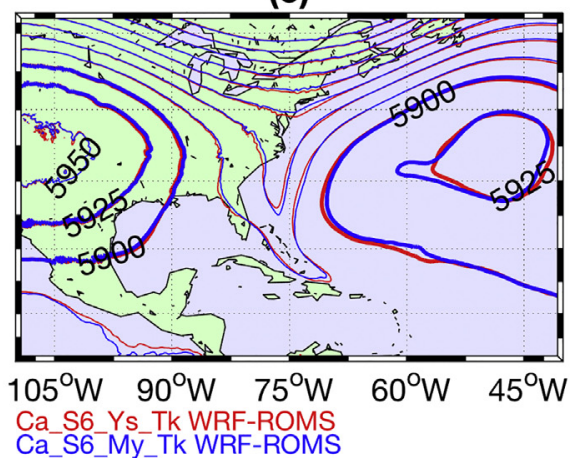

(g)

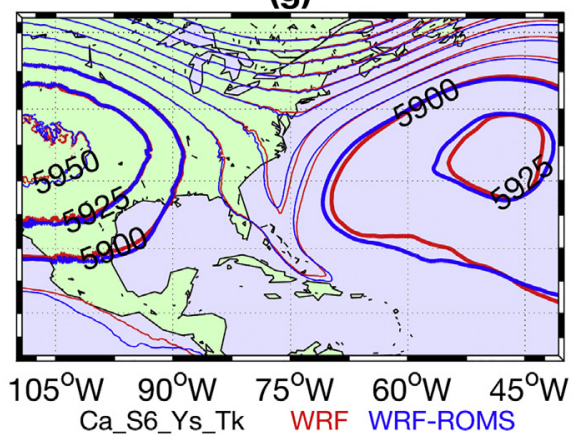

Fig. 4. (a). Contour plot of the $500 \mathrm{hPa}$ geopotential height averaged over the 23-28th of August 2011 from the Ca_S6_Ys_KF (red) and Ca_S6_Ys_Tk (blue) simulations using WRF-only. (b) Same as (a) except for Ca_S6_Ys_KF (red) and Ca_S6_My_KF (blue) with WRF only. (c) Same as (a) except for Ca_S6_Ys_Tk (red) and Ca_S6_My_Tk (blue) with WRF-only. (d) Same as (b) except with WRF-ROMS. (e) Same as (c) except with WRF-ROMS. (f) Same as (a) except for Ca_S6_Ys_KF with WRF (red) and WRF-ROMS (blue). (g) Same as (a) except for Ca_S6_Ys_Tk with WRF (red) and WRF-ROMS (blue). (For interpretation of the references to colour in this figure legend, the reader is referred to the web version of this article.) 
(a)

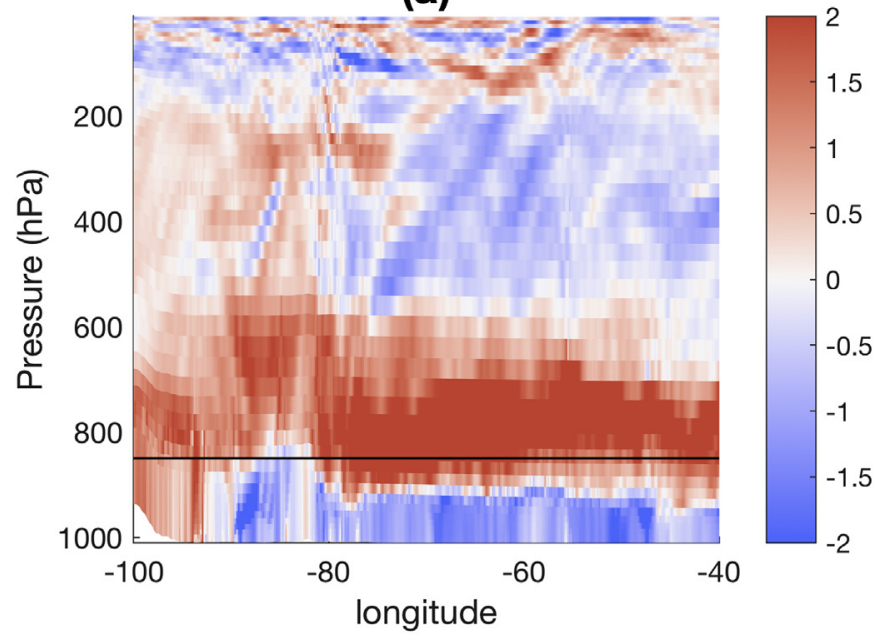

(c)

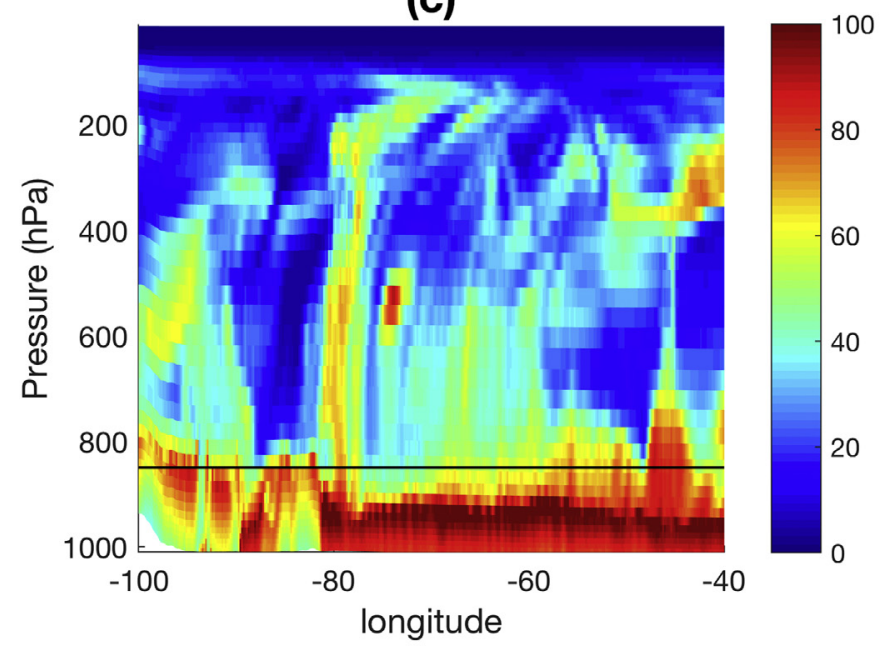

(e)

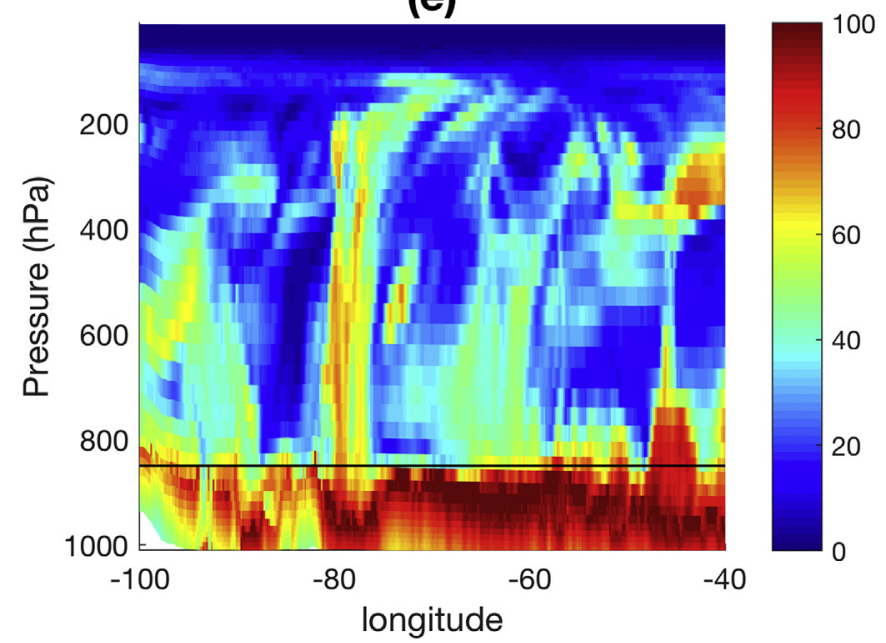

(b)

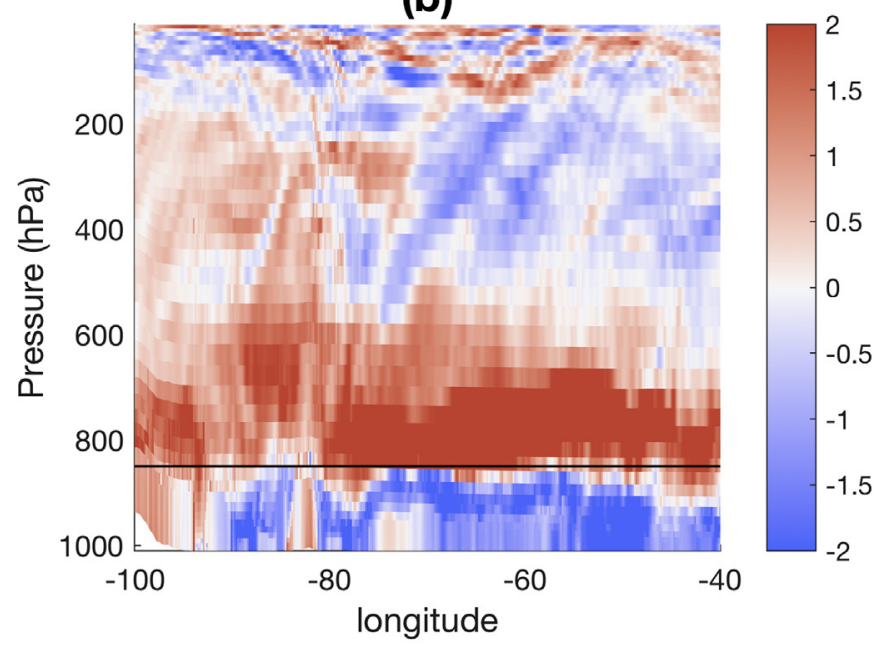

(d)

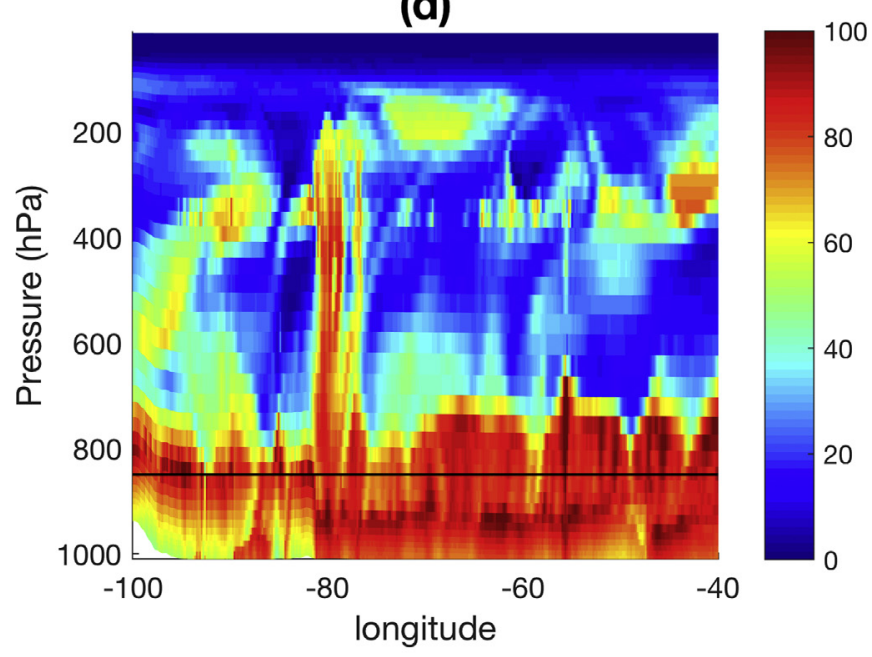

(f)

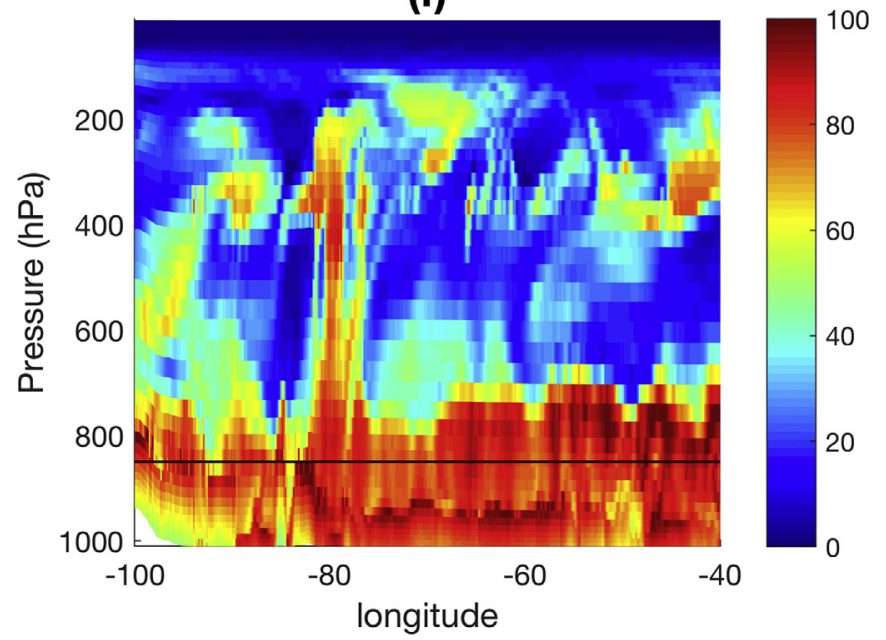

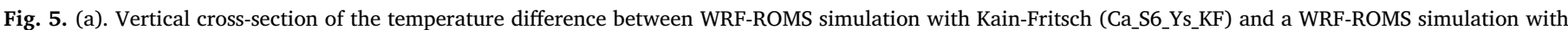

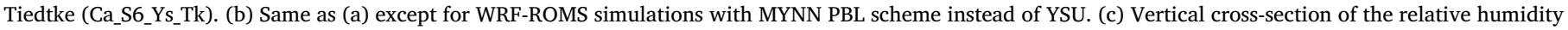

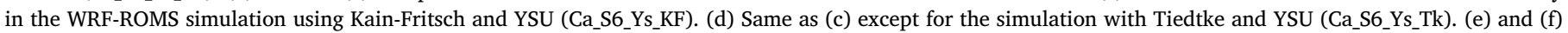

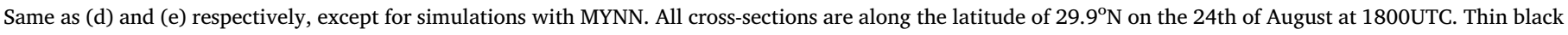
line shows the $850 \mathrm{hPa}$ level. 


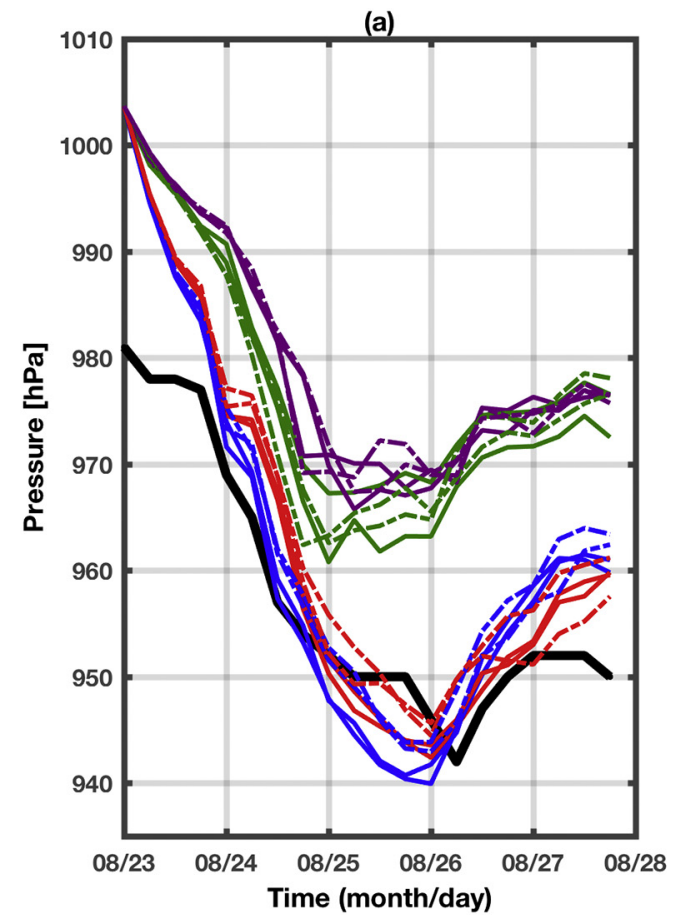

(b)

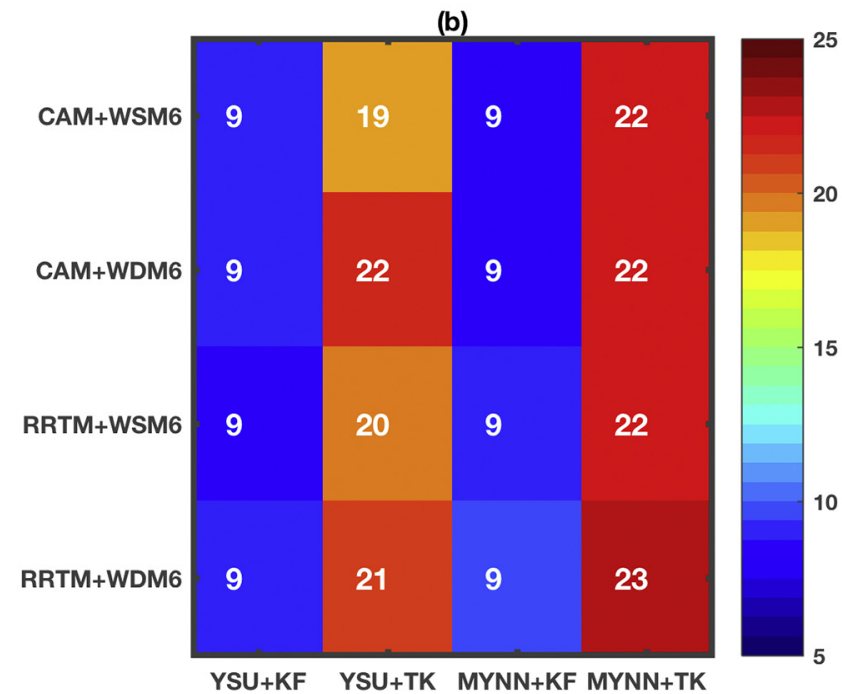

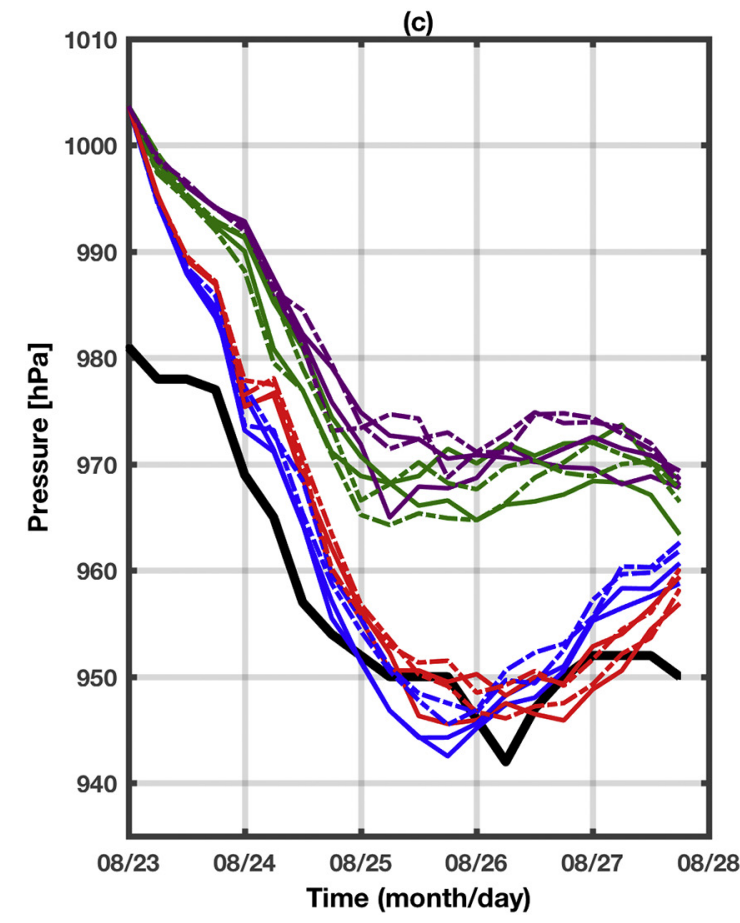

(d)

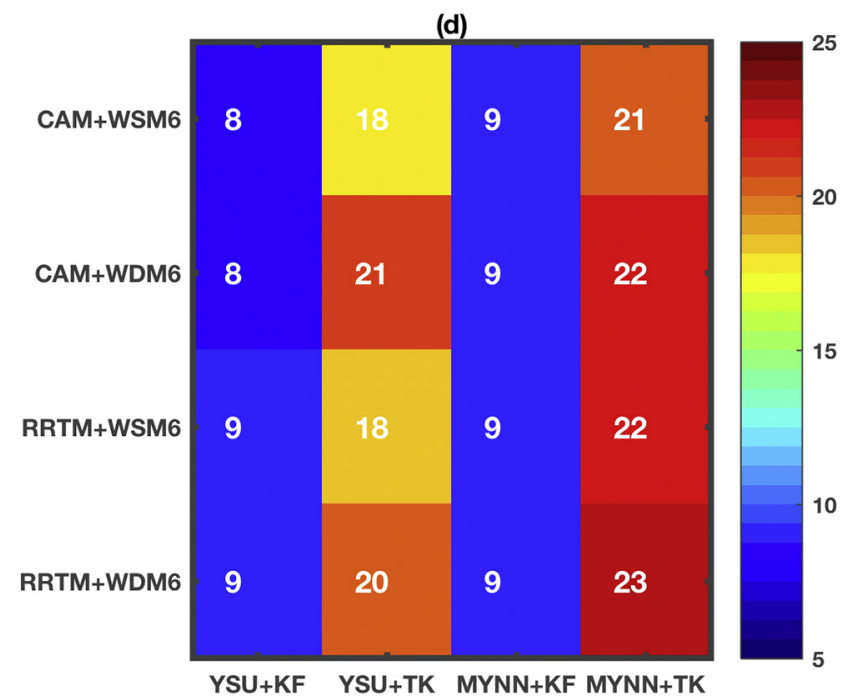

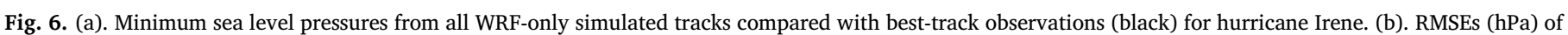

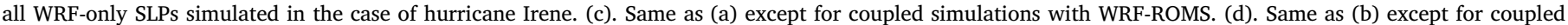
simulations with WRF-ROMS.

geopotential field, the location of the subtropical high extends slightly more westward in the coupled simulation. This leads to only a slight westward shift in the tracks simulated with Tk, which marginally improves the model's skill in the simulated track.

\subsubsection{Transport of heat and moisture in the lower troposphere}

Previous research by Torn and Davis (2012) showed that differences in the representation of shallow convection between cumulus schemes could substantially alter the simulated large-scale temperature and wind fields, which largely influences the simulated tracks. Shallow convection in a cumulus scheme is responsible for transporting moist air from the well-mixed boundary layer into the lower troposphere (Parker et al., 2017). In this study, the varying sensitivity of the simulated subtropical ridge and subsequent tracks with the cumulus schemes can be attributed to differences in the representation of shallow convection in the schemes and the differing interaction with the PBL schemes. Fig. 5(a) and (b) show a vertical cross-section of the temperature differences between two pairs of WRF-ROMS simulations as a function of longitude at a latitude of $29.9^{\circ} \mathrm{N}$ (i.e., near the subtropical high) on August 24th at 1800 UTC (the time when the recurvature of TC Irene was taking place). Fig. 5(a) shows the temperature difference between $\mathrm{KF}$ and Tk simulations using the YSU scheme, while Fig. 5(b) shows the temperature difference between $\mathrm{KF}$ and $\mathrm{Tk}$ simulations using the MYNN scheme. The largest temperature differences (at $800 \mathrm{hPa}$ and below) are mostly over the oceanic portion of the domain $(40-80 \mathrm{~W})$. These figures demonstrate that the simulated temperatures are cooler for KF at the surface to $850 \mathrm{hPa}$ level but warmer than Tk in the 800-600 hPa level. Fig. 5(c)-(f) show a vertical crosssection of relative humidity at the same latitude and time as the temperature differences in Fig. 5(a) and (b) for four different WRF-ROMS 
simulations: KF-YSU, Tk-YSU, KF-MYNN, and Tk-MYNN. These figures show that simulations with the Tk scheme have greater mixing and redistribution of heat and moisture from the surface to the $800 \mathrm{hPa}$ level. Importantly, these figures demonstrate that the Tk scheme has a more active shallow convection and therefore more moisture transported into the lower troposphere from the PBL than simulations with $\mathrm{KF}$. The difference in representation of shallow convection in the KF and Tk cumulus schemes can therefore lead to substantial differences in the geopotential heights and consequently the differences in TC tracks previously discussed.

While a number of previous studies have examined the sensitivity of TC track to cumulus scheme (e.g. Torn and Davis, 2012; Shepherd and Walsh, 2017; Parker et al., 2017), this study also explores how the interaction of the cumulus scheme with the PBL scheme affects the track outcome. Since the Tk scheme's active shallow convection transports more moist air into the lower troposphere than $\mathrm{KF}$, simulations with Tk are therefore less sensitive to the choice of PBL scheme than simulations with the KF cumulus scheme. Fig. 5(c) show that the vertical distribution of relative humidity in the KF and YSU simulation changes gradually from high humidity to low humidity. This contrasts with the distribution of humidity in KF simulations with MYNN (Fig. 5(e)) which have a high humidity below $850 \mathrm{hPa}$ and low humidity above $850 \mathrm{hPa}$. This difference between the two simulations in the vertical distribution of moisture near the top of the boundary layer is due to the inclusion of non-local effects in the YSU scheme, which allows entrainment of dry air from the free atmosphere into the PBL. This contrasts with the MYNN scheme, where non-local effects are not included. Therefore, simulations with the KF cumulus scheme are highly sensitive to the choice of PBL scheme in the simulation.

Simulations with the KF scheme are also more sensitive to coupling than simulations with the Tk scheme. This might be expected since simulations with $\mathrm{KF}$ are sensitive to the PBL schemes and moisture is mostly concentrated in the PBL in these simulations. As such, these simulations are more sensitive to changes in the ocean surface and therefore the coupling with ROMS. Conversely, the active shallow convection, transport of moisture aloft, and insensitivity to PBL scheme, reduces the sensitivity of the Tk simulations to changes to the ocean surface with ROMS coupling. This explains the consistency in the simulated TC track with the Tk cumulus scheme between WRF only and WRF-ROMS simulations (see Fig. 3b).

\subsection{TC intensity}

Fig. 6 shows the observed and simulated minimum mean sea level pressures for TC Irene. In all simulations Irene starts with a pressure that is approximately $20 \mathrm{hPa}$ too high. Previous research (e.g. Rogers et al., 2006; Zambon et al., 2014; Parker et al., 2017) has remarked on the difficulty of accurately representing the intensity of strong TCs at model initialization. In the case of Irene, the differences in pressure can be partially attributed to the coarse horizontal grid spacing $\left(0.75^{\circ}\right)$ in the forcing data (ERA-Interim) used to initialize the simulations. In this study, numerous simulations were performed (not shown) to identify the optimal start time for initialization. Although WRF has multiple options to improve the initial conditions, e.g. data assimilation and digital filter initialization, none of these options were used in this study since they are not typically used in regional climate studies.

Fig. 6(a)-(d) show a clear and consistent influence of the physics parameterizations on the simulated pressures. Simulations using the Tk cumulus scheme (green and purple lines in Fig. 6(a) and (c)) consistently produce pressures that are substantially higher than the observations while the simulations with KF (red and blue lines in Fig. 6(a) and (c)) are in good agreement with the observations. This difference in central pressure between the KF and Tk simulations is evident in both the WRF-ROMS simulations and the WRF-only simulations. Varying other parameterizations schemes has very little influence on the simulated pressures. Furthermore, our results demonstrate that coupling does not substantially alter the simulated pressures (Fig. 6). This can be partially explained by the similarity between the sea surface temperatures (SSTs) simulated by the ROMS model in the coupled simulations and the SSTs in the ERA-Interim data that is used in the WRF-only simulations. This is discussed further in section 4.5.

\subsubsection{Shallow convection}

Section 4.1.2 demonstrated the effect of different representations of shallow convection in the KF and Tk schemes on the simulated track. Changes in simulated intensity are also sensitive to the representation of shallow convection in the contrasting cumulus schemes. Shallow convection is poorly represented over the tropical ocean in the KF scheme (Torn and Davis, 2012), whereas the Tk scheme has a more active shallow convection scheme over the ocean and the moisture flux through the cloud base is assumed to be equivalent to the surface moisture flux (Torn and Davis, 2012). A vertical cross section of the relative humidity simulations with contrasting cumulus schemes after $42 \mathrm{~h}$ is shown in Fig. 5(c) and (d). The simulation using KF shows high relative humidity, primarily in the well-mixed boundary layer, which contrasts with the Tk simulation that shows high relative humidity up to $\sim 700 \mathrm{hPa}$. This demonstrates the effect of the more active shallow convection on the simulations with Tk, which results in greater upward transport of moisture across the boundary layer inversion. The more active shallow convection of the Tk scheme reduces the deep convective mass flux and buoyancy, reducing the TC intensification rate (Torn and Davis, 2012). This reduction would account for the weaker TC intensity simulated with the Tk scheme in this study. Conversely, without the shallow convection over the tropical oceans (Torn and Davis, 2012), the KF scheme does not reduce the deep convective mass flux, thereby giving rise to an increasing intensification rate, which results in greater simulated intensities as indicated by central pressure.

\subsection{TC translational speed}

The translational speed (or forward speed) of a TC affects the ground relative wind speed and flood inundation at landfall, and therefore the resulting coastal impacts (e.g. Shapiro, 1983; Rego and Li, 2009; Czajkowski and Done, 2014). Fig. 7(a-b) show the percentage error of the calculated mean translational speeds throughout the WRFonly and WRF-ROMS simulations. All simulations have a positive percentage error, which indicates that all simulations have slower translational speeds than the observed. The lower percentage errors in Fig. 7(b) compared to Fig. 7(a) show that WRF-ROMS generally simulates more accurate translational speeds than WRF-only simulations. The coupling between the ocean and atmospheric components in this model set up provides a more physically realistic representation of the interaction between the TC and the ocean. This interaction improves the accuracy of the simulated translational speed.

In both the WRF-only and WRF-ROMS simulations, Irene's simulated translational speed is dependent on the choice of both the cumulus and PBL scheme. This is due to the sensitivity of the simulated track to the choice of cumulus scheme and the interaction between the cumulus and PBL scheme as discussed in detail in Section 4.1. KF-YSU simulations have the lowest percentage error, which shows they simulate the most accurate translational speeds compared to the other experiments. Simulated translational speeds with the YSU PBL scheme generally outperform those using the MYNN scheme. Similarly, KF simulations have more accurate translational speeds than their Tk equivalents. Tk-MYNN simulations produce the slowest translational speeds.

\subsection{TC rainfall rate}

The TC rainfall rate is examined here, since the associated rainfall can often be the most damaging aspect of a TC to coastal areas (Walsh, 2004). Fig. 8(a) and (b) show the time evolution of the simulated and observed mean rainfall rate $(\mathrm{mm} / \mathrm{h})$ along a $\sim 400 \mathrm{~km}$ swath centred 
(a)

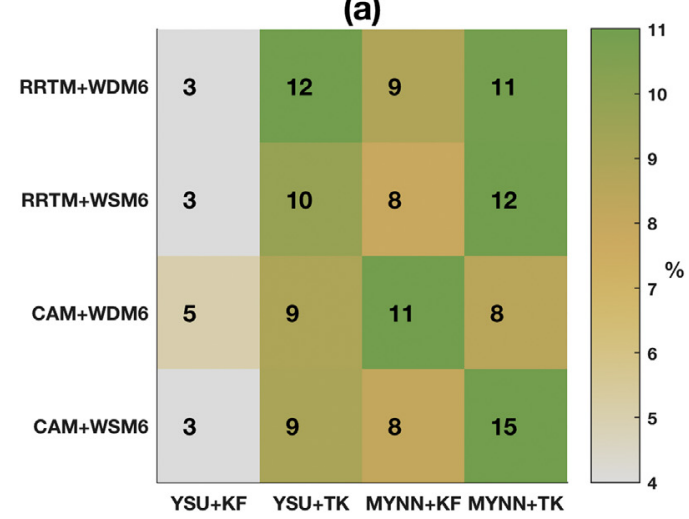

(b)

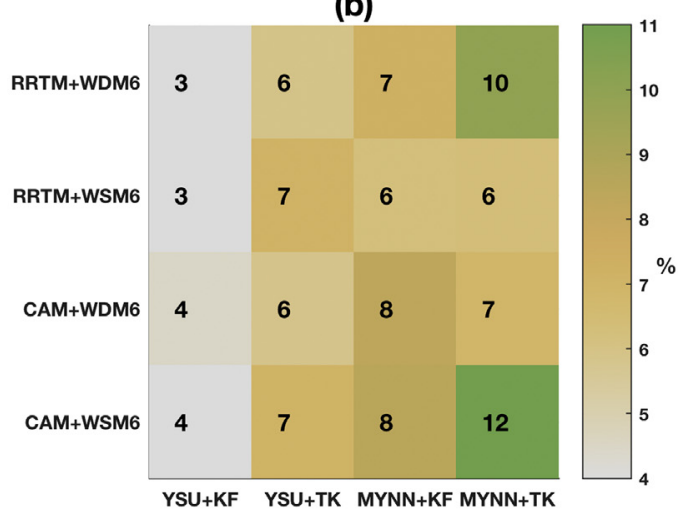

Fig. 7. (a). Percentage errors in the mean translational speed simulated by WRF-only over the 5-day period. (b) Same as (a) except for WRF-ROMS.

along the TC track. Both WRF-only and WRF-ROMS show a distinct influence of the cumulus parameterizations on rainfall rate. The KF simulations considerably overestimate the mean rainfall after the first $24 \mathrm{~h}$, while Tk simulations are in better agreement with the mean rainfall observed in TRMM. Simulations using the KF cumulus scheme also show that the PBL schemes influence the simulated rainfall. The influence of the PBL on the simulated rainfall is also evident in simulations using Tk. As discussed in Section 4.1.2, particularly when using the KF cumulus scheme, the PBL parameterization affects the vertical distribution of humidity in the atmosphere and will therefore have a strong influence on the resulting precipitation in the simulation. The overestimation in rainfall in the KF simulations is likely due to the parameterization of shallow convection. KF has a less active shallow convection scheme than $\mathrm{Tk}$, which leads to the development of more deep convection in the KF simulations. As a result of this, the KF simulations produce more rainfall than the Tk simulations.Neither the radiation nor the microphysics schemes show an influence on the simulated rainfall. Coupling ROMS to WRF did not substantially alter the simulated TC rainfall. The only noticeable impact of coupling was the increased rainfall in the simulations with $\mathrm{KF}$ towards the end of the simulations that is not evident in the WRF-only simulations.

\subsection{Sea surface temperatures}

Since one of the major advantages of coupling ROMS to WRF is a more physically representative sea surface, this section evaluates the quality of the simulated SSTs and investigates their role in the simulated intensities for TC Irene. Fig. 9 shows the satellite-derived SSTs from OSTIA (top row), the SSTs used in all WRF-only simulations (second row), the SSTs modeled by the KF-YSU WRF-ROMS (third row) simulation for TC Irene, and the SSTs from HYCOM (bottom row). Comparing Fig. 9(a) and (b) with Fig. 9(d) and (e) shows that the preand post-storm SSTs from OSTIA and those used in the WRF-only simulations are very similar. This similarity between the SSTs is a result of obtaining WRF-only values from ERA-Interim which are derived from OSTIA. The main difference is that the WRF-only SSTs are obtained on a coarser grid $(\sim 75 \mathrm{~km})$ than OSTIA $(\sim 6 \mathrm{~km})$. Compared to the coarser SSTs in the WRF-only simulations, OSTIA shows a slightly larger area of cooling to the right of the storm track and slightly greater cooling. This is more apparent in the plots on the right of Fig. 9, which show the difference between pre- and post-storm SSTs.

The SSTs simulated by WRF-ROMS (Fig. 9, third row) show a colder wake with a more intricate pattern than the OSTIA wake (Fig. 9, top
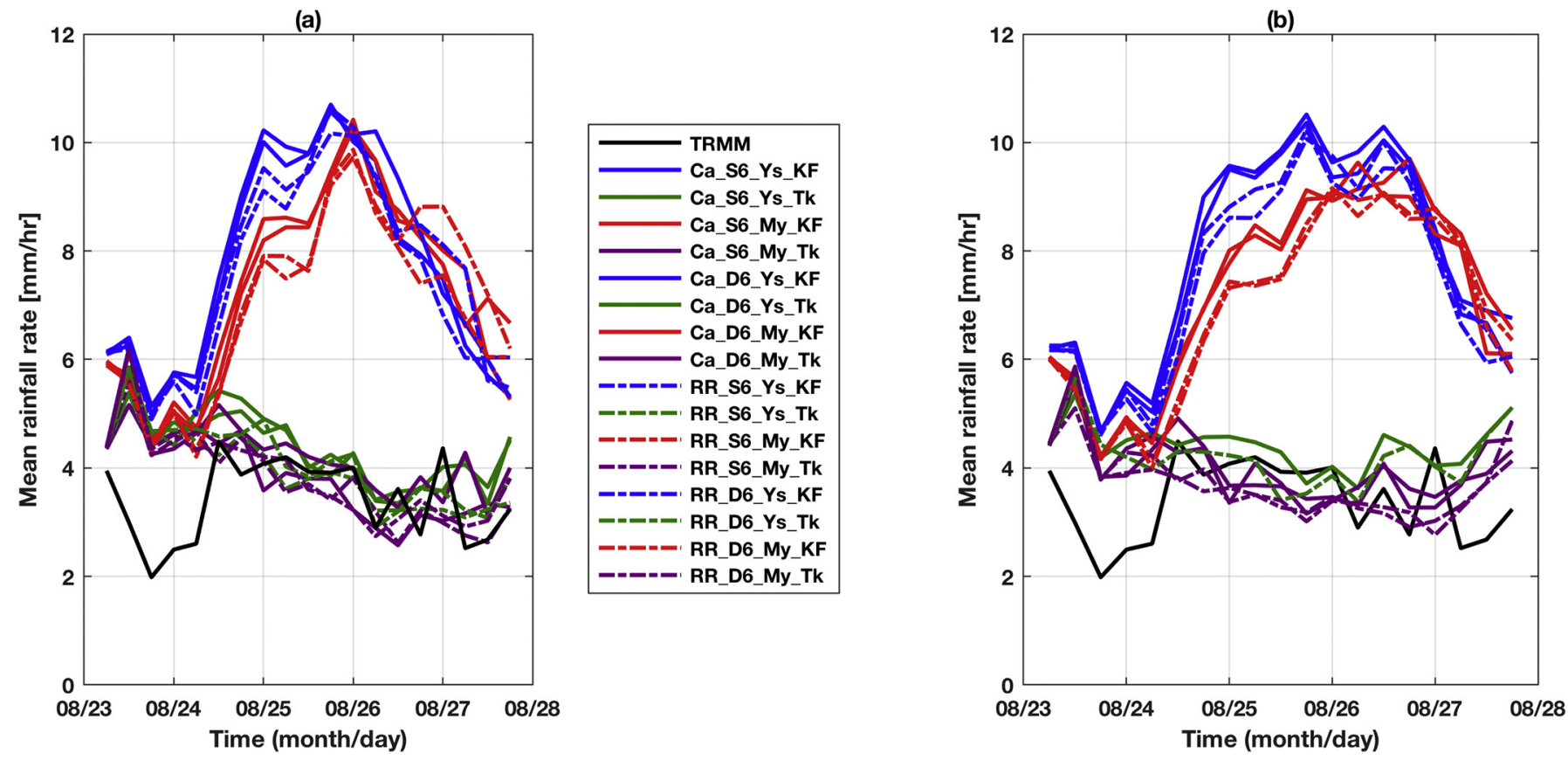

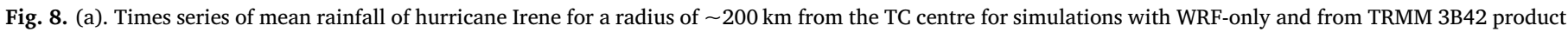
over the 5-day period. (b) Same as (a) except for WRF-ROMS. 


\section{3/08 Pre-storm}

(a)

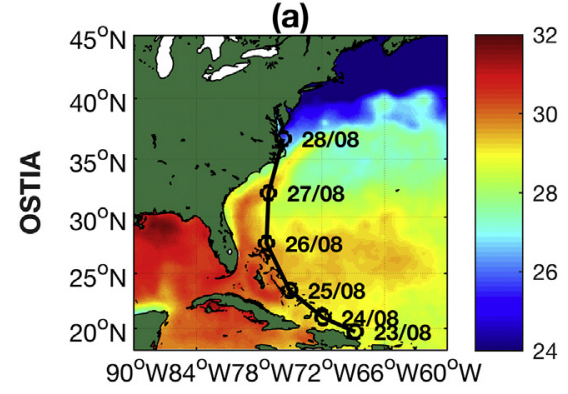

(d)

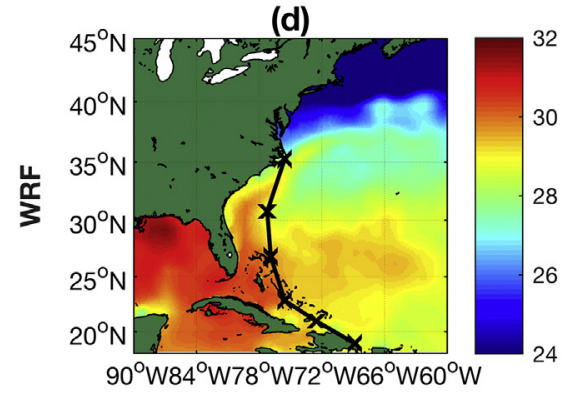

(g)

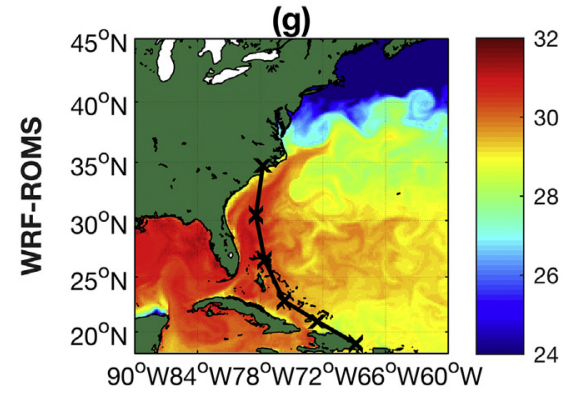

(j)

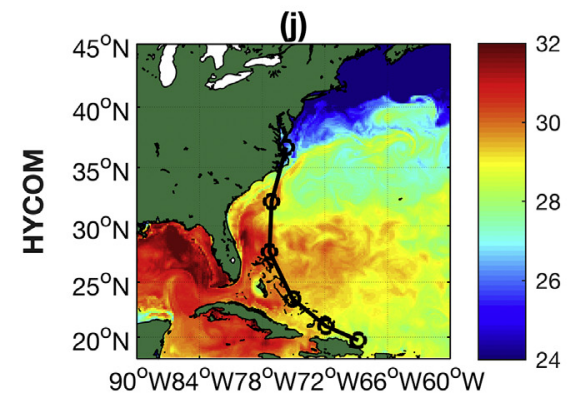

27/08 - Post-storm

(b)

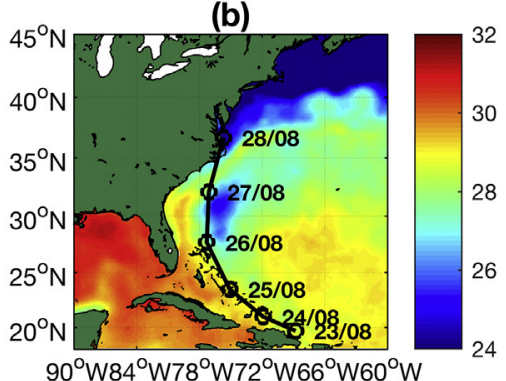

(e)

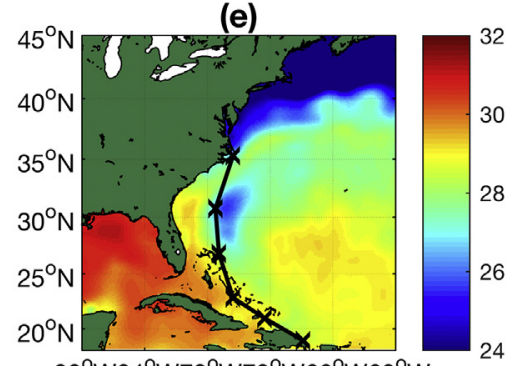

(h)

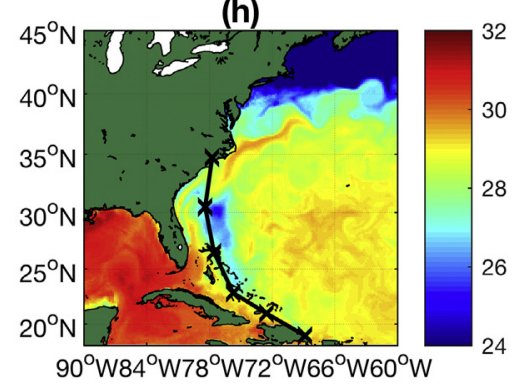

(k)

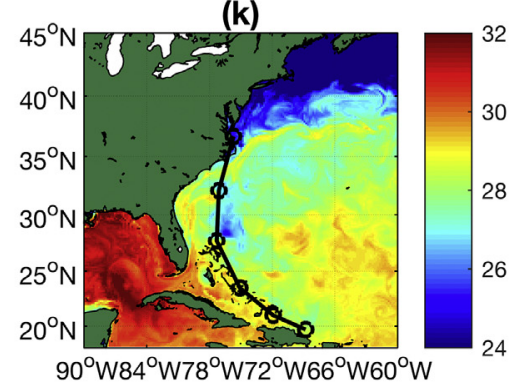

$\Delta$ SST

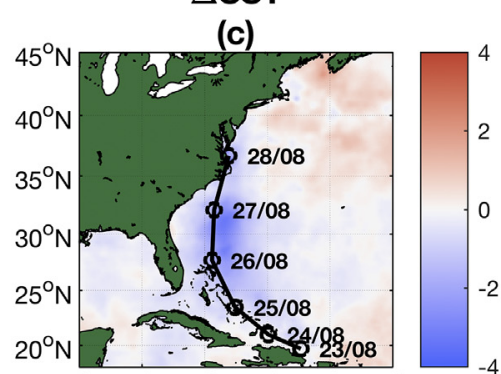

$90^{\circ} \mathrm{W} 84^{\circ} \mathrm{W} 78^{\circ} \mathrm{W} 72^{\circ} \mathrm{W} 66^{\circ} \mathrm{W} 60^{\circ} \mathrm{W}$

(f)

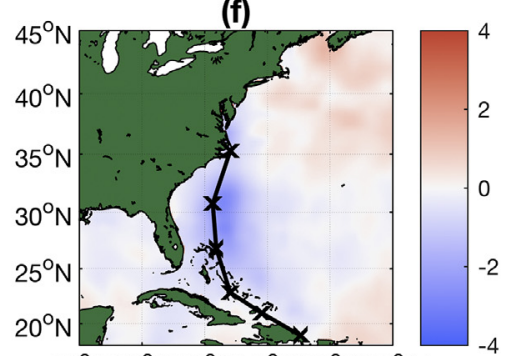

$90^{\circ} \mathrm{W} 84^{\circ} \mathrm{W} 78^{\circ} \mathrm{W} 72^{\circ} \mathrm{W} 66^{\circ} \mathrm{W} 60^{\circ} \mathrm{W}$

(i)

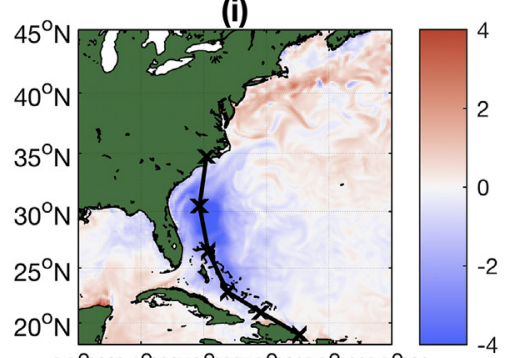

$90^{\circ} \mathrm{W} 84^{\circ} \mathrm{W} 78^{\circ} \mathrm{W} 72^{\circ} \mathrm{W} 66^{\circ} \mathrm{W} 60^{\circ} \mathrm{W}$

(I)

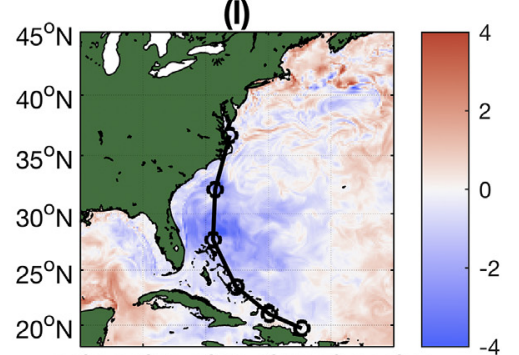

$90^{\circ} \mathrm{W} 84^{\circ} \mathrm{W} 78^{\circ} \mathrm{W} 72^{\circ} \mathrm{W} 66^{\circ} \mathrm{W} 60^{\circ} \mathrm{W}$

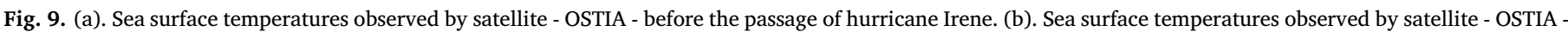

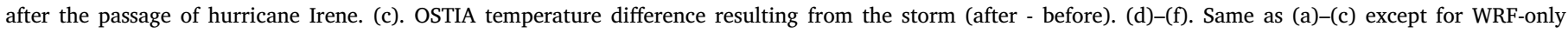
(Ca_S6_Ys_KF). (g)-(i). Same as (a)-(c) except for WRF-ROMS (Ca_S6_Ys_KF). (j)-(1). Same as (a)-(c) except for HYCOM.

row). A notable difference in the simulated WRF-ROMS SSTs is the larger area of cooling on the left side of the track compared to OSTIA. This is largely due to the slower speed of the simulated TC compared to the observed translation speed of TC Irene, allowing for greater vertical mixing of cooler waters from beneath the thermocline. Right of the track, the cold wake is similar in magnitude to OSTIA. The WRF-ROMS SSTs also differ from those in HYCOM (Fig. 9, bottom row), which provides ROMS with initial and boundary conditions. HYCOM's SSTs show less cooling than the WRF-ROMS SSTs and the OSTIA SSTs but the cooling in HYCOM's SSTs is over a larger area than the cooling in the WRF-ROMS and OSTIA SSTs.

Since the track in each simulation differs, the SST beneath the TC track in each simulation could be very different. A substantial difference between the surface temperatures encountered by the TC in the different simulations would change the amount of heat energy available for TC intensification in each simulation. Consequently, the surface temperature beneath the storm at each 6-h interval is examined to identify the impact of surface temperatures on the simulated intensities. Fig. 10(a) and (b) show the surface temperature averaged over a $2^{\circ} \times 2^{\circ}(\sim 80$ grid cells) domain centered on the storm at each interval for each simulation using WRF and WRF-ROMS. At some intervals, this $2^{\circ} \times 2^{\circ}$ domain contains large portions of land due to the numerous islands located in the region. These temperatures were included in the domain average as they also impact the heat energy available for intensification. Fig. 10(c) and (d) show the percentage of the domains covered by land for each simulation at each interval. Given the 
(a)

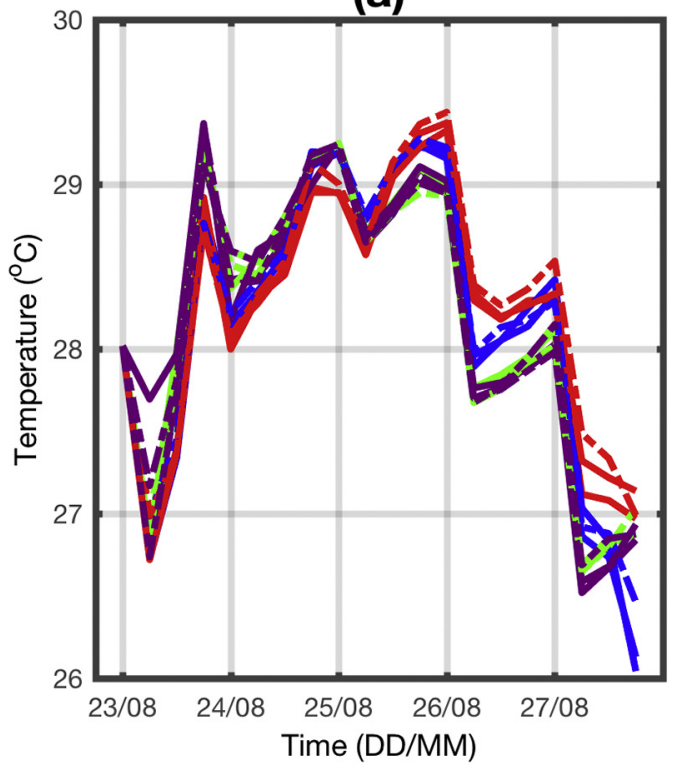

(c)

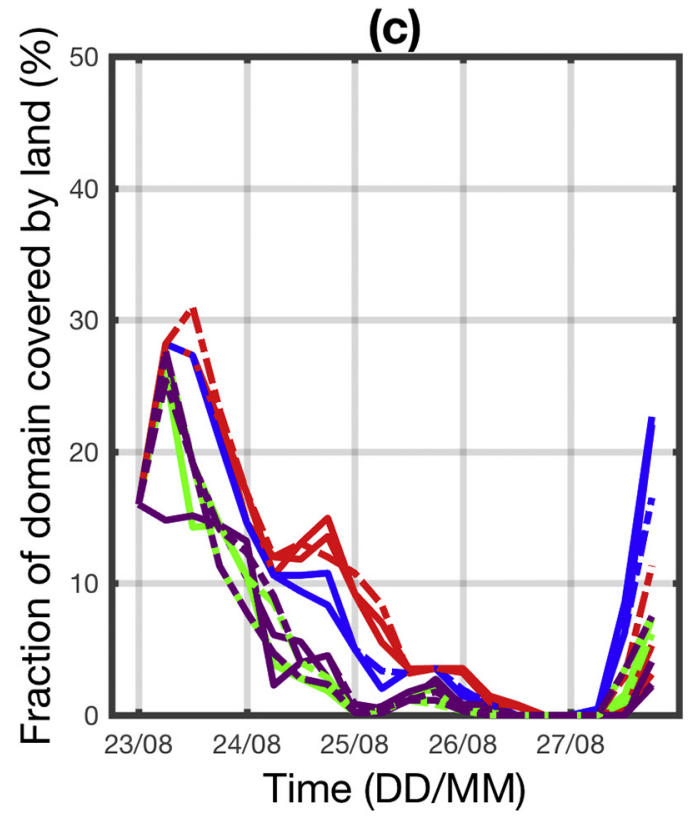

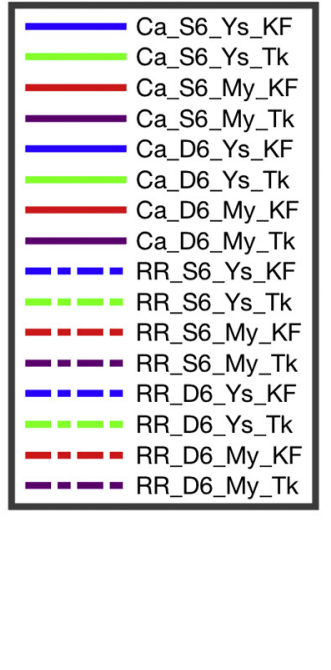

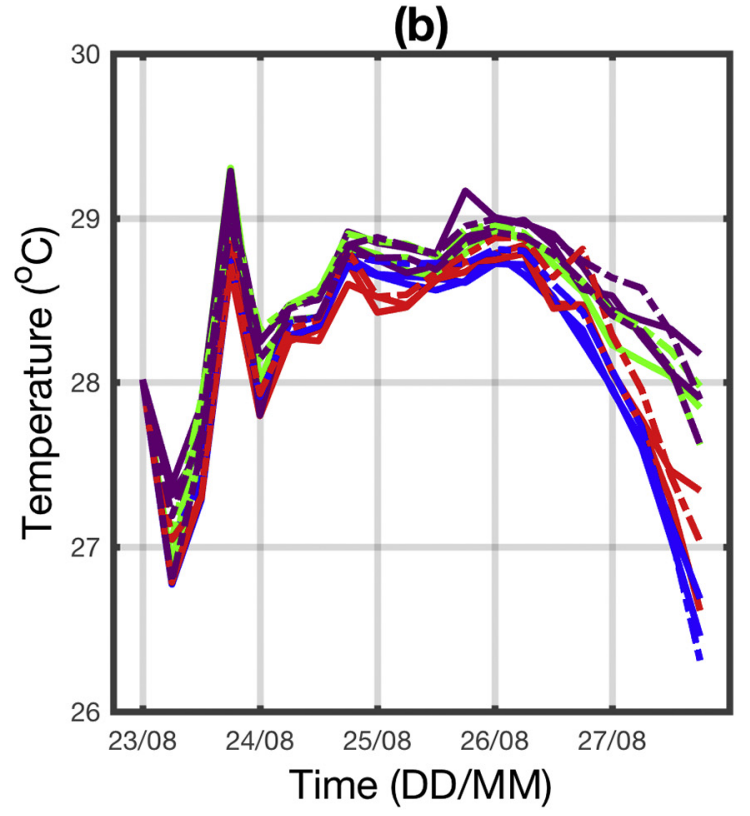

(d)

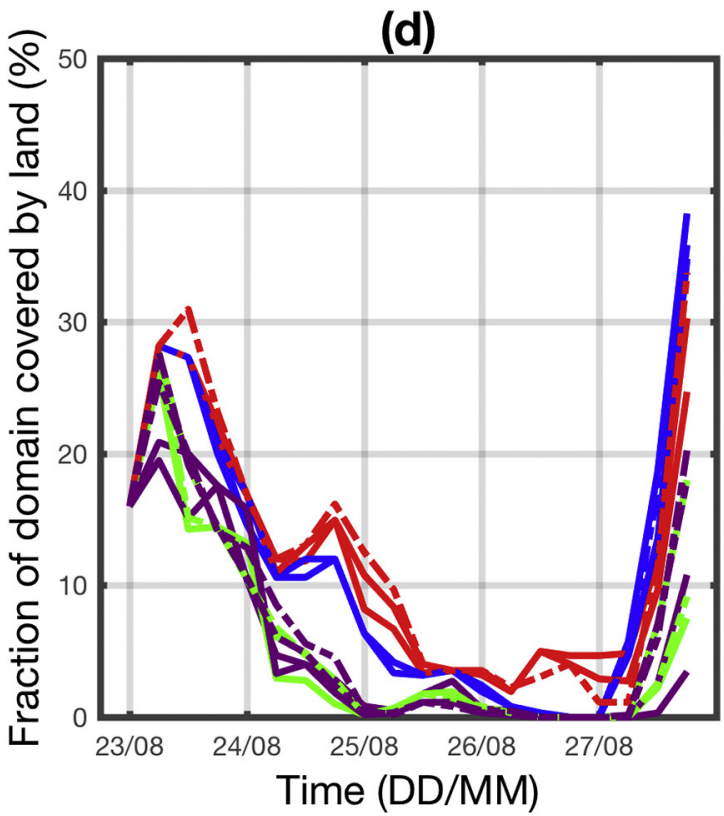

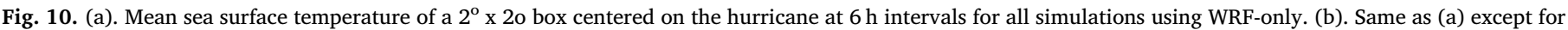

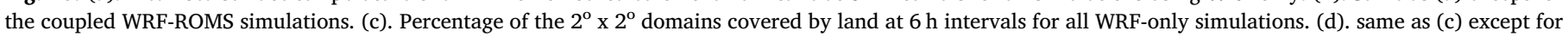
the coupled WRF-ROMS simulations.

inclusion of land in these boxes, temperatures shown in Fig. 10(a) and (b) will hereafter be referred to as skin temperature.

Skin temperatures beneath the hurricane at 6-h intervals using either WRF or WRF-ROMS showed substantial changes over the first $24 \mathrm{~h}$. This behavior is likely due to the initial adjustments in the simulation and the large $(\sim 30 \%)$ area of land included in the skin temperature analysis. After the first $24 \mathrm{~h}$, skin temperatures in the WRF simulations show gradual increases throughout the day before decreasing rapidly at the start of the next day. These rapid changes are coincident with the daily update of SSTs from ERA-Interim. WRF-ROMS simulations show no abrupt changes in temperature over the remaining 4 days which is more realistic than the WRF simulations.

Fig. 10(a) and (b) show that the average skin temperatures experienced by the TC in the WRF-only simulations are very similar to those in the coupled simulations. This similarity in the skin temperatures shows that the amount of energy available for intensification is comparable for coupled and non-coupled simulations. This explains why coupling has a negligible influence on simulated minimum pressures. There is also very little difference in skin temperature between KF and Tk simulations even though the TC simulated with either cumulus scheme moves along different tracks. This similarity between the skin temperatures encountered by the simulated TCs suggests that differences in intensity between the KF and Tk simulations, and coupleduncoupled simulations cannot be attributed to the SSTs but mostly to the differences in the shallow convection of the cumulus schemes as discussed in Section 4.2.

\section{Summary}

In this study of Irene, the simulated intensities and rainfall rates 
with WRF-only and WRF-ROMS simulations at a $12 \mathrm{~km}$ horizontal grid spacing, show a clear sensitivity to the cumulus schemes while the simulated tracks and translational speeds show sensitivity to cumulus scheme and the combination of cumulus scheme and PBL scheme. Parameterizations of radiation and microphysical process did not influence the simulated tracks, intensities and translational speeds. However, rainfall rates exhibited a small sensitivity to radiation when simulated with the KF cumulus scheme.

The optimal combinations of physics parameterizations depend largely on which TC characteristic is of primary interest. In this study, optimal combinations for WRF-only where the focus is on either or all of Irene's track, intensity and/or translational speed are those simulations that use the KF cumulus scheme and the YSU PBL scheme. However, if the focus is on the rainfall rate, then the optimal combinations are the Tk cumulus scheme and of the radiation, PBL and microphysics schemes. The optimal set of parameterizations for the WRFROMS system is also different depending on which TC characteristic is more important. In studies where the intensity or translational speed is the main focus, the optimal set of parameterizations for simulating TC Irene is the KF cumulus scheme, the YSU PBL scheme and either of the radiation and microphysics schemes. However, if the track or rainfall rate is of primary importance, then the optimal set of physics is the Tk cumulus scheme and any of the schemes in the PBL, radiation and microphysics categories.

\section{Conclusions}

Before drawing any conclusions from these results, it is noted that simulating only one TC limits the generalization of the results found in this study. To address this issue, the study was repeated for a second TC, namely Ophelia (2011) and the results are presented separately in Appendix A. The following conclusions are presented based on the results of both TCs and/or the similarity of other studies in the literature.

The sensitivity of the storm tracks to cumulus parameterizations found here, and also in previous studies (Torn and Davis, 2012; Parker et al., 2017), is largely due to the treatment of shallow convection in the two cumulus parameterizations. Tk has a more active shallow convection than KF, which leads to differences in the large-scale flow responsible for steering the hurricane. For this study the cumulus scheme simulated differences in the subtropical ridge which affected the westward shift of the TC trajectories. These differences are evident in all simulations whether or not WRF is coupled to ROMS and independently of different schemes selected in the other parameterization categories. This result is not unique to Irene, and it applies to any TC that is strongly influenced by this flow pattern. This is an important result for regional climate simulations since it would influence the number of land-falling TCs simulated depending on the choice of cumulus parameterizations.

Importantly, this study also found that simulations with the KF cumulus scheme are distinctly sensitive to the PBL scheme chosen, while those that use the Tk scheme do not exhibit this PBL sensitivity. This relative sensitivity is likely controlled by the difference in vertical distribution of moisture and the treatment of its upward transport by the shallow convection in the cumulus schemes. The choice of PBL scheme with KF resulted in notable differences in the subtropical high which subsequently altered the track. This finding demonstrates the complexity of selecting optimal parameterization schemes for simulations. The sensitivity findings highlighted in this study demonstrate that the cumulus and PBL schemes need to be chosen carefully for regional climate modeling configurations with horizontal grid spacings $>10$ $\mathrm{km}$. However, it is important to consider that the sensitivities found in this study may be altered in longer climate simulations. Whether or not coupling influences the track cannot be concluded from this study, since the results for both Irene and Ophelia were inconsistent. However, coupling did show a clear and consistent improvement in the simulated translational speeds. Coupling ROMS to WRF did not substantially influence the intensities, as represented by the mean sea level pressure, because SSTs in the vicinity of the TC are similar in both the WRF and WRF-ROMS simulations.

For future TC studies and regional climate simulations, this study highlights that coupling ROMS to WRF can substantially alter the optimal selection of physics parameterizations. The optimal combination of physics parameterizations in the WRF-only simulations then produced poorer tracks in the WRF-ROMS simulations. This demonstrates that, in some cases, coupling an ocean model to WRF can actually degrade the simulation of certain TC characteristics that are important for regional climate studies of TCs. Nonetheless, coupling provides a better representation of the oceanic conditions and the air-sea interactions that become increasingly important at longer time scales and with future climate change. An example in this study is where the improved representation of the air-sea interactions through coupling, increased the accuracy of the TC translational speed simulation.

Coupling ROMS to WRF at the grid scale used here $(12 \mathrm{~km})$ brings both advantages and disadvantages which need careful consideration when designing regional climate modeling studies of TCs. At higher resolutions, such as grid spacings $<4 \mathrm{~km}$, simulations begin to resolve convective processes (Done et al., 2004) and cumulus parameterizations are no longer required. Clearly, such simulations will have no sensitivity to cumulus schemes, but it is reasonable to expect increased sensitivity to the parameterization of processes in the PBL and at the air-sea interface at these convection-permitting scales.

This study highlights the importance of case study-based simulations and demonstrates the need to undertake physics sensitivity tests and in depth analyses prior to application at the regional-climate scale with coupled ocean-atmosphere modeling systems. This study has demonstrated that simulations have varying sensitivities to physics schemes and results from previous sensitivity studies with WRF-only simulations are not always transferable to coupled simulations. Furthermore, this study shows that the physics schemes can interact with each other in different ways. Therefore, the choice of physics combinations has a substantial influence on the outcome of the simulation.

\section{Acknowledgements}

P.A. Mooney acknowledges funding from the Irish Research Council, co-funded by Marie Curie Actions under FP7. NCAR is sponsored by the National Science Foundation. This work was partially supported by NSF EASM Grant AGS-1048829 and the Research Partnership to Secure Energy for America. The authors acknowledge high-performance computing support from Yellowstone (ark:/85065/ d7wd3xhc) provided by NCAR's Computational and Information Systems Laboratory, sponsored by the National Science Foundation. ECMWF ERA-Interim data used in this study has been obtained from the ECMWF data server: http://data.ecmwf.int/data. OSTIA data was provided by GHRSST, UKMO and MyOcean. Part of the data analysis in this work was undertaken with climate data operators (CDO, 2015) and the commercial software package MATLAB ${ }^{\circledR}$. The authors are grateful to Dr. John Warner (USGS, Woods Hole) for providing access to the COAWST modeling system.

\section{Appendix A. Case study of Ophelia (2011)}

While Irene passed over shallow water for several days before making landfall, Ophelia was chosen for this study because its path was almost entirely over deep ocean and it occurred during the same season as Irene. It was considered that these conditions would facilitate a useful test of the general results obtained for Irene. In this study, Ophelia is simulated from the 28th of September to the 3rd of October 2011. Ophelia became a 
tropical storm around 0600 UTC on the 28th of September and developed into a hurricane on the 29th, acquiring major hurricane status on the 30th of September. On the 2nd of October, Ophelia reached its estimated peak intensity and accelerated north-northeastward weakening rapidly. By 0600 UTC on the 3rd of October, Ophelia had weakened to a tropical storm and later that day to an extra-tropical storm.

\section{A.1. Experimental setup}

Best tracks and sea-level pressure for Ophelia were obtained from the US National Hurricane Center's reports on Ophelia (Cangialosi, 2011). Observed precipitation data was obtained from the Tropical Rainfall Measuring Mission on a $0.25^{\circ}$ grid from https://disc.gsfc.nasa.gov/datasets/ TRMM_3B42_7/summary accessed on the 18th of May 2018.

The simulations of Ophelia use the same model configuration and domains as those used for Irene (see section 3.3 and Fig. 2). Simulations of TC Ophelia cover the period from 0000 UTC on the 28th of September 2011 to 0000 UTC on 3rd of October 2011. The different parameterizations for the WRF and WRF-ROMS simulations are shown in Table 2.

\section{A.2. Results}

Fig. A1(a)-(d) show the best-observed track, modeled tracks, and their RMSE values for Ophelia. In Fig. A1(a) and (c), the simulated tracks appear to be in good agreement with the best-observed track for TC Ophelia. Comparing the RMSE values for Irene's tracks (shown in Fig. 3(b) and (d)) with Ophelia's (Fig. A1(b) and (d)) shows that the simulated tracks for Irene are more accurate than the simulated tracks for Ophelia. The intensity of Irene is also more accurately simulated than Ophelia's (See Fig. 4(a)-(d) and Fig. A2(a)-(d)). WRF simulations, with the notable exceptions of those using Tk, capture the intensity of Irene very well but reproduce only the early part of Ophelia's intensification. This is consistent with the reports by Avila and Cangialosi (2011) and Cangialosi (2011) which used forecast errors to show that the storm track of Irene was easier than average to forecast while Ophelia was harder than average at long range (4-5 days) forecast times.

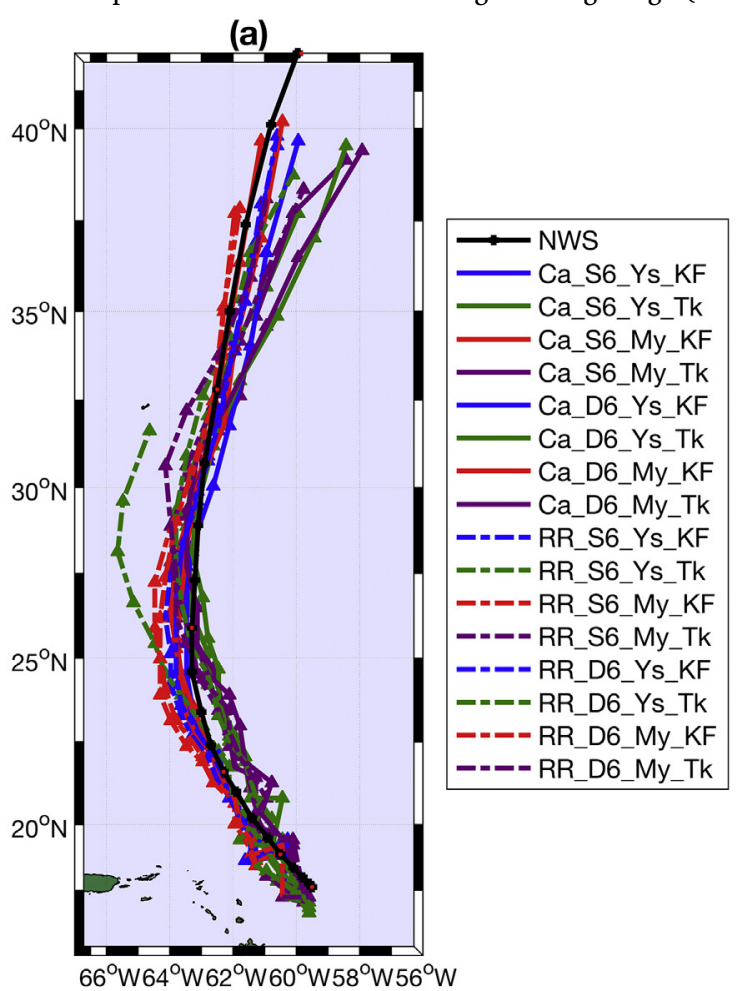

(c)

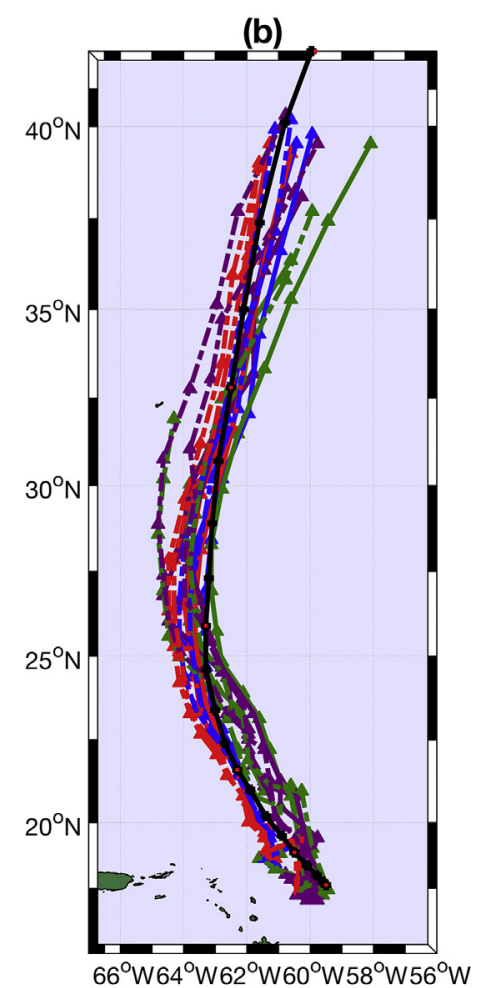

(d)
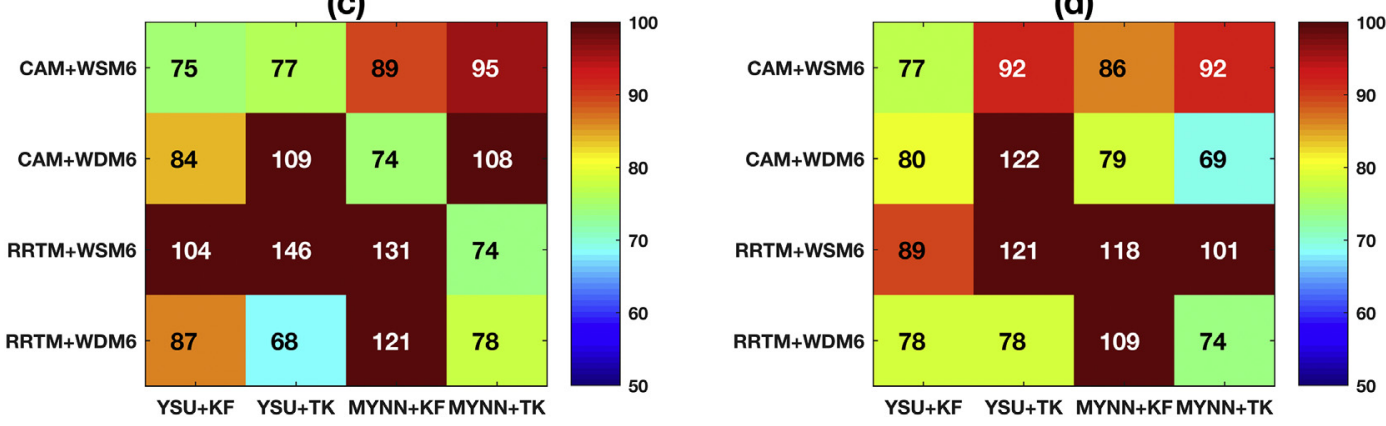

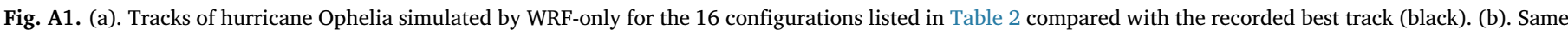

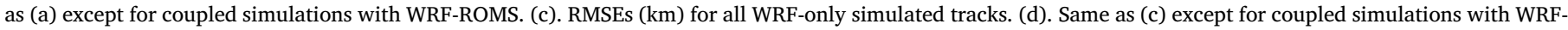
ROMS. 


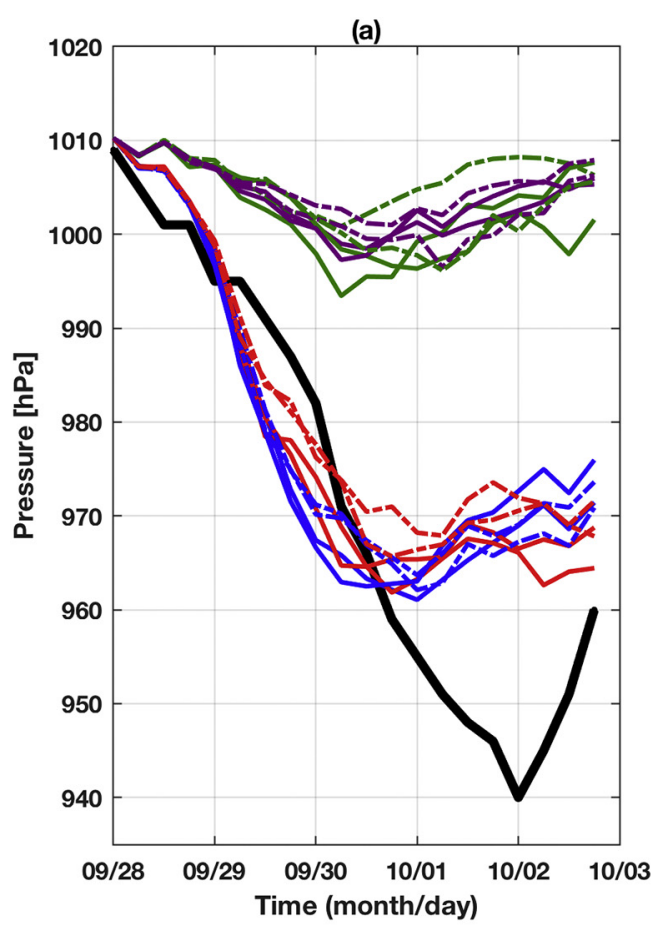

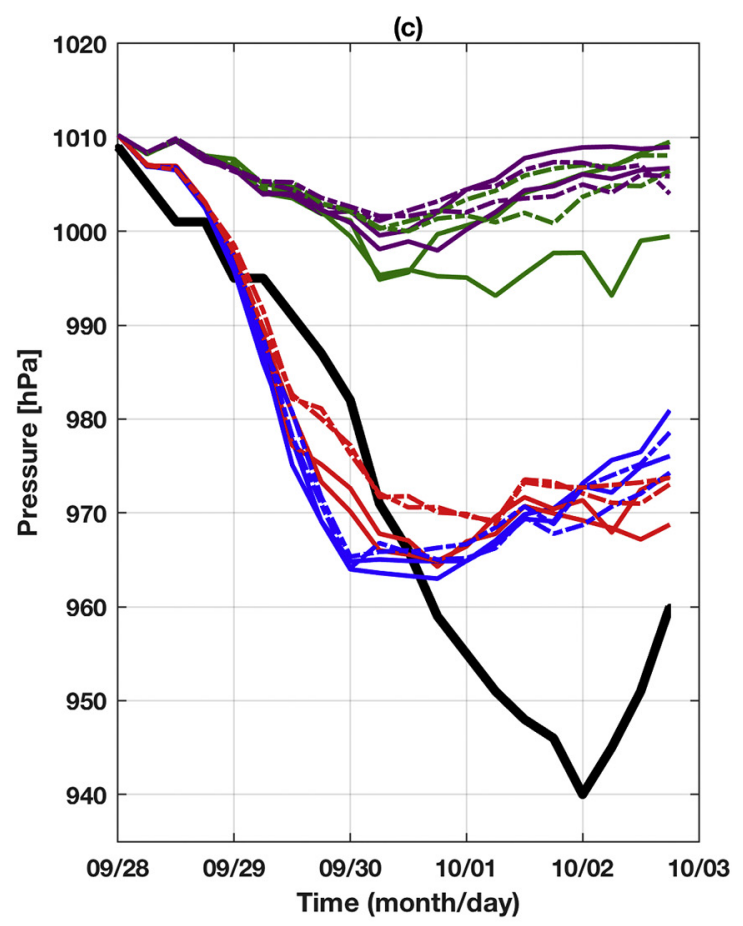

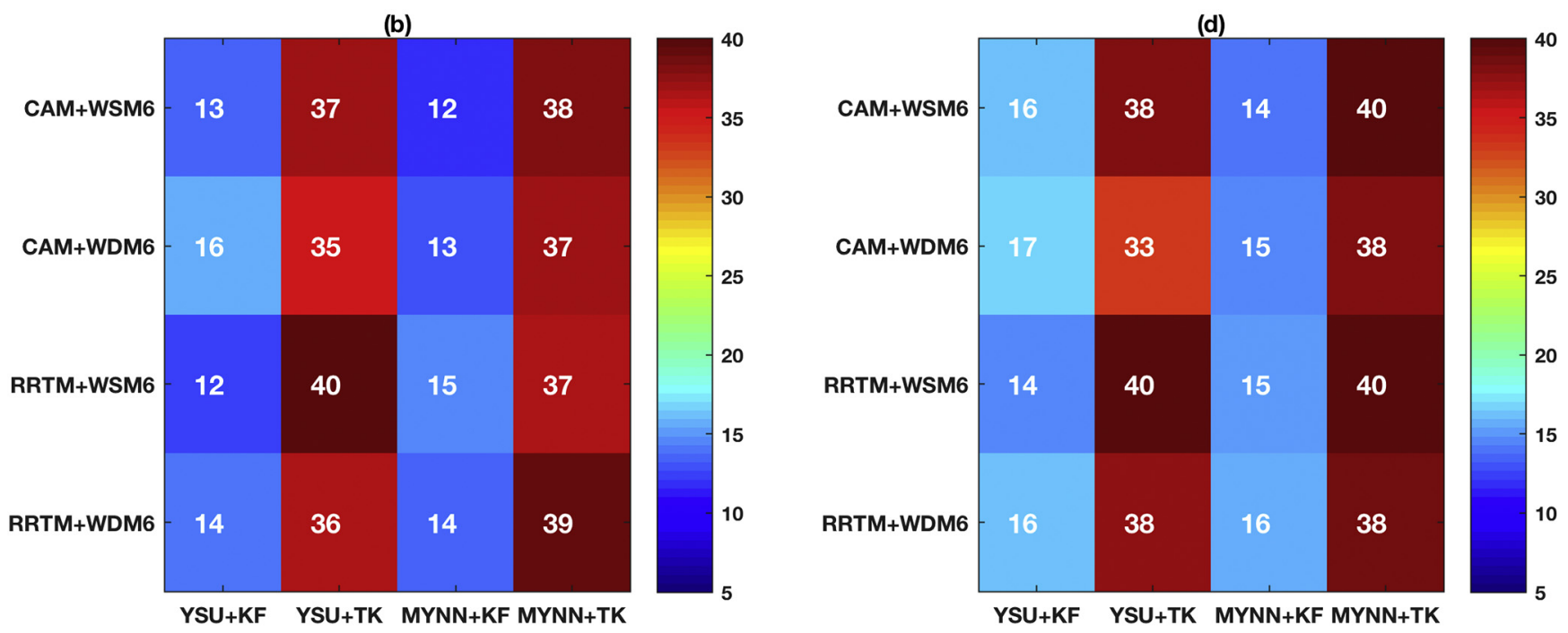

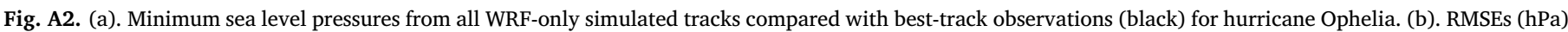

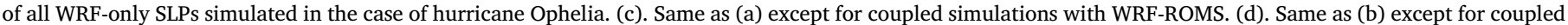
simulations with WRF-ROMS.

\section{A.2.1. Influence of WRF parameterizations}

Figs. A1-A4 show the influence of the physics parameterizations on Ophelia's simulated track, intensity, rainfall rate and translational speed. Of these four TC characteristics, only simulated tracks of Ophelia show no clear influence by the different parameterizations. There is no specific category of parameterization that consistently improves or degrades the simulated track of Ophelia. This differs from the simulated tracks of Irene (Fig. 3), which were strongly influenced by the cumulus and PBL schemes. 
(a)

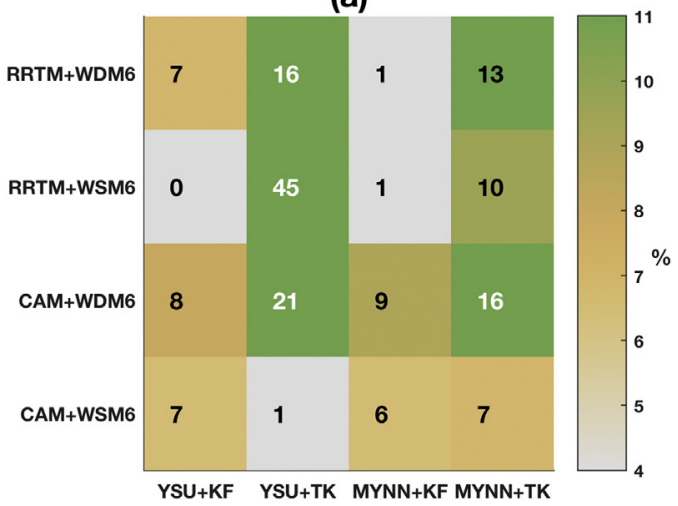

(b)

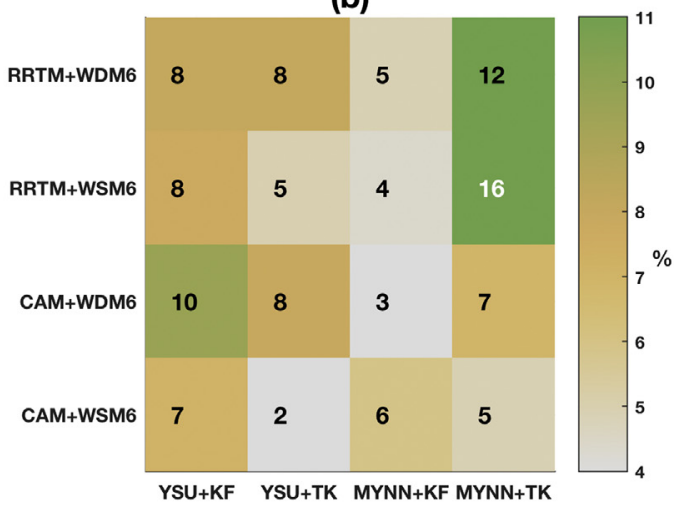

Fig. A3. (a) Percentage errors in the mean translational speed simulated by WRF-only over the 5-day period. (b) Same as (a) except for WRF-ROMS.

(a)

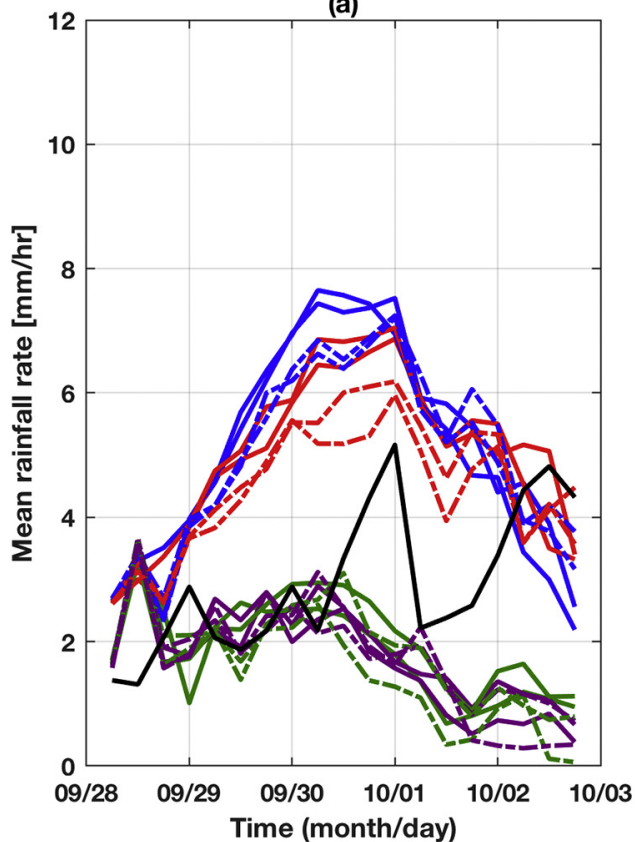

(b)

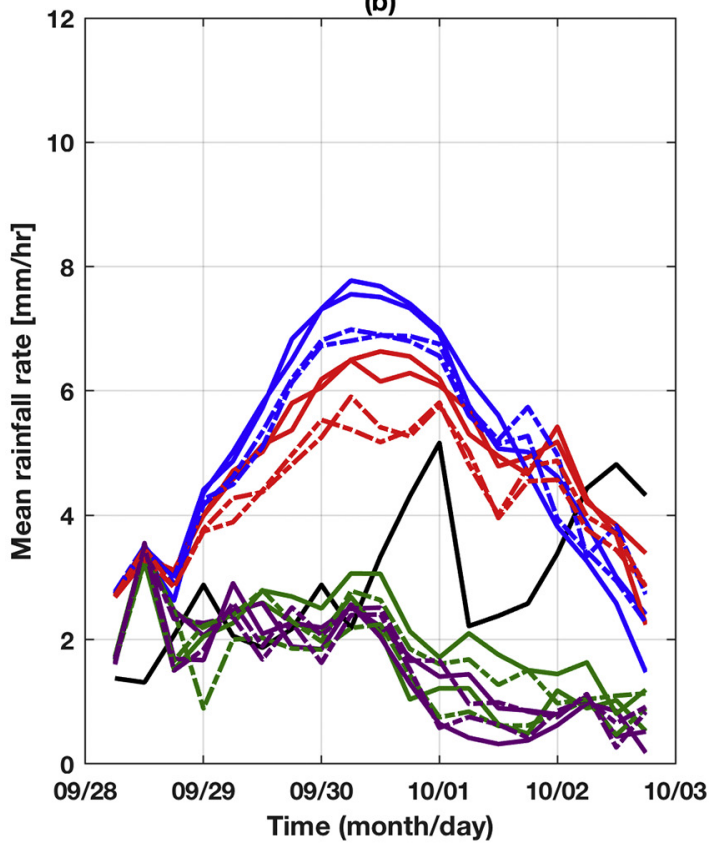

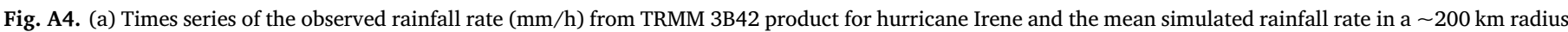
from the TC centre over the 5-day period in (a) simulations with WRF-only and (b) WRF-ROMS simulations.

Fig. A2(a)-(d) show a clear and consistent influence on the simulated pressures by the physics parameterizations. In both hurricanes, Tk si-

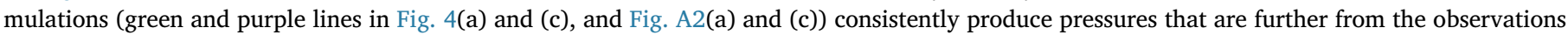

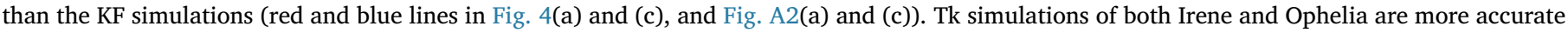
when using the YSU PBL scheme than the MYNN PBL scheme.

Fig. A3(a)-(b) show that cumulus schemes strongly influence the simulated translational speed with KF simulations outperforming Tk simula-

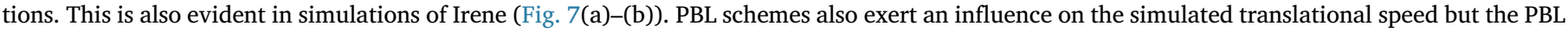
influence is smaller in Ophelia simulations than in the Irene simulations.

The simulated rainfall rate for Ophelia is shown in Fig. A4(a)-(b). The simulated rainfall rate is substantially influenced by the cumulus schemes

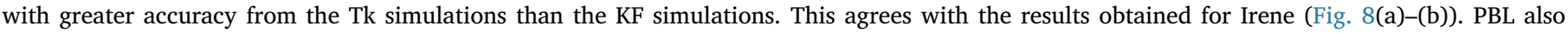

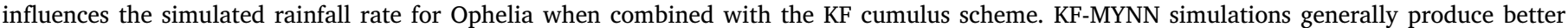
rainfall rates than the KF-YSU simulations. This also agrees with the findings for Irene (Fig. 8(a)-(b)).

\section{A.2.2. Coupling with an ocean model}

Fig. A1(a)-(d) show that generally, coupling the ocean model to WRF leads to poorer track prediction for Ophelia as indicated by the higher RMSE values for WRF-ROMS simulations compared with WRF-only simulations. Fig. A3 shows that coupling did influence the translational speed of Ophelia leading to more accurate translational speeds. This result is also evident in Fig. 7(a)-(b) for TC Irene. In agreement with the simulations of Irene, coupling did not influence the simulated intensity and rainfall rate of Ophelia. Simulations of Ophelia also show that the optimal combination of physics parameterizations for WRF-only is not necessarily optimal for WRF-ROMS.

\section{References}

Avila, L.A., Cangialosi, J., 2011. Tropical Cyclone Report: Hurricane Irene, NOAA
National Hurricane Center Reports. pp. 1-45.

Balaguru, K., Taraphdar, S., Leung, L.R., Foltz, G.R., Knaff, J.A., 2014. Cyclone-cyclone interactions through the ocean pathway. Geophys. Res. Lett. 41, 6855-6862. https:// doi.org/10.1002/2014GL061489. 
Bao, J.-W., Wilczak, J.M., Choi, J.-K., Kantha, L., 2000. Numerical simulations of air-sea interaction under high wind conditions using a coupled model: a study of hurricane development. Mon. Weather Rev. 128, 2190-2210.

Bender, M.A., Ginis, I., 2000. Real-case simulations of hurricane-ocean interaction using a high- resolution coupled model: Effects on hurricane intensity. Mon. Weather Rev. 128, 917-946.

Bender, M.A., Ginis, I., Tuleya, R., Thomas, B., Marchok, T., 2007. The operational GFDL coupled hurricane- ocean prediction system and a summary of its performance. Mon. Weather Rev. 135, 3965-3989.

Bender, M.A., Knutsen, T.R., Tuleya, R.E., Sirutis, J.J., Vecchi, G.A., Garner, S.T., Held, I.M., 2010. Modeled impact of anthropogenic warming on the frequency of intense Atlantic hurricanes. Science 327, 454-458.

Blake, E.S., Landsea, C.W., Gibney, E.J., 2011. The Deadliest, Costliest, and Most Intense United States Tropical Cyclones from 1851 to 2010 (and Other Frequently Requested Hurricane Facts), NOAA Technical Memorandum NWS NHC-6. www.nhc.noaa.gov/ pdf/nws-nhc-6.pdf.

Booij, N., Ris, R.C., Holthuijsen, L.H., 1999. A third-generation wave model for coastal regions. Part I: model description and validation. J. Geophys. Res. 104, 7649-7666. https://doi.org/10.1029/98JC02622.

Bruyère, C.L., Holland, G.J., Towler, E., 2012. Investigating the use of a genesis potential index for tropical cyclones in the North Atlantic Basin. J. Clim. 25, 8611-8626. https://doi.org/10.1175/JCLI-D-11-00619.1.

Cangialosi, J., 2011. Tropical Cyclone Report: Hurricane Ophelia, NOAA National Hurricane Center Reports. pp. 1-16.

CDO, 2015. Climate Data Operators. Available at. http://www.mpimet.mpg.de/cdo.

Chen, S.S., Zhao, W., Donelan, M.A., Price, J.F., Walsh, E.J., 2007. The CBLAST-hurricane program and the next-generation fully coupled atmosphere-wave-ocean models for hurricane research and prediction. Bull. Am. Meteorol. Soc. 88, 311-317. https://doi. org/10.1175/BAMS-88-3-311.

Collins, W.D., Rasch, P.J., Boville, B.A., Hack, J.J., McCaa, J.R., Williamson, D.L., Kiehl, J.T., Briegleb, B., Bitz, C., Lin, S.-J., Zhang, M., Dai, Y., 2004. Description of the NCAR Community Atmosphere Model (CAM3.0). NCAR Technical Note, TN$464+$ STR. pp. 102-143.

Cummings, J.A., 2005. Operational multivariate ocean data assimilation. Quart. J. Royal Met. Soc. Part C 131 (613), 3583-3604.

Czajkowski, J., Done, J., 2014. As the wind blows? Understanding hurricane damages at the local level through a case study analysis. Weather Clim. Soc. 6 (2), 202-217.

Dare, R.A., McBride, J.L., 2011. Sea surface temperature response to tropical cyclones. Mon. Weather Rev. 139 (12), 3798-3808.

Davis, C., Wang, W., Dudhia, J., Torn, R., 2010. Does increased horizontal resolution Improve hurricane wind forecasts? Weather Forecast. 25, 1826-1841. https://doi. org/10.1175/2010WAF2222423.1.

Dee, D.P., Uppala, S.M., Simmons, A.J., Berrisford, P., Poli, P., Kobayashi, S., Andrae, U., Balmaseda, M.A., Balsamo, G., Bauer, P., Bechtold, P., Beljaars, A.C.M., van de Berg, L., Bidlot, J., Bormann, N., Dlesol, C., Dragani, R., Fuentes, M., Geer, A.J., Haimberger, L., Healy, S.B., Hersbach, H., Hólm, E.V., Isaken, L., Källberg, P., Kohler, M., Matricardi, M., McNally, A.P., Monge-Sanz, B.M., Morcrette, J.-J., Park, B.-K., Peubey, C., de Rosnay, P., Tavoloato, C., Thépaut, J.-N., Vitart, F., 2011. The ERA Interim reanalysis: configuration and performance of the data assimilation system. Quart. J. Royal Met. Soc. 137, 553-597. https://doi.org/10.1002/qj.828.

Doi, T., Vecchi, G.A., Rosati, A.J., Delworth, T.L., 2013. Response to $\mathrm{CO}_{2}$ doubling of the Atlantic hurricane main development region in a high-resolution climate model. J. Clim. 26, 4322-4334. https://doi.org/10.1175/JCLI-D-12-00110.1.

Done, J.M., Davis, C., Weisman, M., 2004. The next generation of NWP: explicit forecasts of convection using the Weather Research and Forecasting (WRF) model. Atmos. Sci. Lett. 5, 110-117. https://doi.org/10.1002/asl.72.

Done, J.M., Holland, G.J., Bruyère, C.L., Leung, L.R., Suzuki-Parker, A., 2013. Modeling high-impact weather and climate: Lessons from a tropical cyclone perspective. Clim. Chang. 129, 381-395. https://doi.org/10.1007/s10584-013-0954-6.

Doocy, S., Dick, A., Daniels, A., Kirsch, T.D., 2013. The human impact of tropical cyclones: a historical review of events 1980-2009 and systematic Literature review. PLOS Curr. Dis. https://doi.org/10.1371/currents.dis. 2664354a5571512063ed29d25ffbce74. Apr 16. Edition 1.

Ek, M., Mahrt, L., 1991. OSU 1-D PBL Model user's Guide. Version1.04, Department of Atmospheric Sciences, Oregon State University, Corvallis, Ore, USA.

Evans, J.P., Ekström, M., Ji, F., 2012. Evaluating the performance of a WRF physics ensemble over South-East Australia. Clim. Dyn. 39, 1241-1258. https://doi.org/10 1007/s00382-011-1244-5.

Flather, R.A., 1976. A tidal model of the northwest European continental shelf. Bull. Soc. Roy. Sci. Liege 6, 141-164.

Glenn, S.M., Miles, T.N., Seroka, G.N., Xu, Y., Forney, R.K., Yu, F., Roarty, H., Schofield, O., Kohut, J., 2016. Stratified coastal ocean interactions with tropical cyclones. Nat. Commun. 7, 10887. https://doi.org/10.1038/ncomms10887.

Gutmann, E.D., Rasmussen, R.M., Liu, C., Ikeda, K., Bruyere, C.L., Done, J.M., ... Veldore, V., 2018. Changes in hurricanes from a 13-Yr convection-permitting pseudo-global warming simulation. J. Clim. 31 (9), 3643-3657.

Hart, R.E., Maue, R.N., Watson, M.C., 2007. Estimating local memory of tropical cyclones through MPI anomaly evolution. Mon. Weather Rev. 135 (12), 3990-4005.

Holland, G.J., Bruyère, C.L., 2014. Recent intense hurricane response to global climate change. Clim. Dyn. 42, 617-627. https://doi.org/10.1007/s00382-013-1713-0.

Hong, S.-Y., Lim, J.-O.J., 2006. The WRF single moment six class scheme (WSM6). J. Korean Meteorol. Soc. 42, 129-151.

Hong, S.-Y., Noh, Y., Dudhia, J., 2006. A new vertical diffusion package with an explicit treatment of entrainment processes. Mon. Weather Rev. 134, 2318-2341.

Iacono, M.J., Delamere, J.S., Mlawer, E.J., Shephard, M.W., Clough, S.A., Collins, W.D., 2008. Radiative forcing by long-lived greenhouse gases: Calculations with the AER radiative transfer models. J. Geophys. Res. 113 (D13103), 1-8. https://doi.org/10. 1029/2008JD009944.

Jacob, D., Petersen, J., Eggert, B., Alias, A., Christensen, O.B., Bouwer, L.M., Braun, A., Colette, A., Deque, M., Georgievski, G., Georgopoulou, E., Gobiet, A., Menut, L., Nikulin, G., Haensler, A., Hempelmann, N., Jones, C., Keuler, K., Kovats, S., Kroner, N., Kotlarski, S., Kriegsmann, A., Martin, E., van Meijgaard, R., Moseley, C., Pfeifer, S., Preuschmann, S., Radermacher, C., Radtke, K., Rechid, D., Rounsevell, M., Samuelsson, P., Somot, S., Soussana, J.-F., Teichmann, C., Valentini, R., Vautard, R., Weber, B., Yiou, P., 2014. EURO-CORDEX: new high-resolution climate change projections for European impact research. Reg. Environ. Chang. 14 (2), 563-578.

Jankov, I., Gallus Jr., W.A., Segal, M., Shaw, B., Koch, S.E., 2005. The impact of different WRF model physical parameterizations and their interactions on warm season MCS rainfall. Weather Forecast. 20, 1048-1060. https://doi.org/10.1175/WAF888.1.

Kain, J.S., 2004. The Kain-Fritsch convective parameterization: an update. J. Appl. Meteorol. 43, 170-181.

Kain, J.S., Fritsch, J.M., 1990. A one-dimensional entraining/detraining plume model and its application in convective parameterization. J. Atmos. Sci. 47, 2784-2802.

Klausmann, A.M., 2014. Analysis of hurricane Irene's wind field using the advanced research weather research and forecast (WRF-ARW) model. J. Mar. Sci. Eng. 2 (1), 33-45. https://doi.org/10.3390/jmse2010033.

Kossin, J.P., Emanuel, K.A., Camargo, S.J., 2016. Past and projected changes in Western North Pacific tropical cyclone exposure. J. Clim. 29, 5725-5739. https://doi.org/10. 1175/JCLI-D-16-0076.1.

Kotlarski, S., Keuler, K., Christensen, O.B., Colette, A., Déqué, M., Gobiet, A., Goergen, K., Jacob, D., Lüthi, D., van Meijgaard, E., Nikulin, G., Schär, C., Teichmann, C., Vautard, R., Warrach-Sagi, K., Wulfmeyer, V., 2014. Regional climate modeling on European scales: a joint standard evaluation of the EURO-CORDEX RCM ensemble. Geosci. Model Dev. 7, 1297-1333. https://doi.org/10.5194/gmd-7-1297-2014.

Larson, J., Jacob, R., Ong, E., 2004. The Model Coupling Toolkit: A New Fortran90 Toolkit for Building Multiphysics Parallel Coupled Models. Preprints, Mathematics and Computer Science Division, Argonne National Laboratory, Argonne, IL.

Lim, K.-S.S., Hong, S.-Y., 2010. Development of an effective double-moment cloud microphysics scheme with prognostic cloud condensation nuclei (CCN) for weather and climate models. Mon. Weather Rev. 28, 1587-1612. https://doi.org/10.1175/ 2009MWR2968.1.

Lin, I., Liu, W.T., Wu, C.-C., Wong, G.T.F., Hu, C., Chen, Z., Liang, W.-D., Yang, Y., Liu, K.K., 2003. New evidence for enhanced ocean primary production triggered by tropical cyclone. Geophys. Res. Lett. 30, 1718. https://doi.org/10.1029/ 2003 GL017141.

Mellor, G.L., Yamada, T., 1982. Development of a turbulence closure model for geophysical fluid problems. Rev. Geophys. Space Phys. 20, 851-875.

Mlawer, E.J., Taubman, S.J., Brown, P.D., Iacono, M.J., Clough, S.A., 1997. Radiative transfer for inhomogeneous atmospheres: RRTM, a validated correlated-k model for the longwave. J. Geophys. Res. 102 (D14), 16663-16682.

Mooney, P.A., Mulligan, F.J., Fealy, R., 2011. Comparison of ERA 40, ERA-Interim and NCEP/NCAR reanalysis data with observed surface air temperatures over Ireland. Int. J. Climatol. 31, 545-557. https://doi.org/10.1002/joc.2098.

Mooney, P.A., Gill, D.O., Mulligan, F.J., Bruyère, C.L., 2016. Hurricane simulation using different representations of atmosphere-ocean interaction: the case of Irene (2011). Atmos. Sci. Lett. 17 (7), 415-421.

Nakanishi, M., Niino, H., 2006. An improved Mellor-Yamada level 3 model: its numerical stability and application to a regional prediction of advecting fog. Bound.-Layer Meteorol. 119, 397-407.

Nakanishi, M., Niino, H., 2009. Development of an improved turbulence closure model for the atmospheric boundary layer. J. Meteor. Soc. Jpn. 87, 895-912.

Park, D.-S.R., Ho, C.-H., Kim, J.-H., 2014. Growing threat of intense tropical cyclones to East Asia over the period 1977-2010. Environ. Res. Lett. 9, 014008. https://doi.org/ 10.1088/1748-9326/9/1/014008.

Parker, C.L., Lynch, A.H., Mooney, P.A., 2017. Factors affecting the simulated trajectory and intensification of Tropical Cyclone Yasi (2011). Atmos. Res. 194, 27-42. https:// doi.org/10.1016/j.atmosres.2017.04.002.

Parker, C.L., Bruyère, C.L., Mooney, P.A., Lynch, A.H., 2018. The Response of LandFalling Tropical Cyclone Characteristics to Projected Climate Change in Northeast Australia, Climate Dynamics, 1-19. https://doi.org/10.1007/s00382-018-4091-9.

Rego, J.L., Li, C., 2009. On the importance of the forward speed of hurricanes in storm surge forecasting: a numerical study. Geophys. Res. Lett. 36 (7).

Rogers, R., Aberson, S., Black, M., Black, P., Cione, J., Dodge, P., Gamache, J., Kaplan, J., Powell, M., Dunion, J., Uhlhorn, E., Shay, N., Surgi, N., 2006. The intensity forecasting experiment: a NOAA multiyear field program for improving tropical cyclone intensity forecasts. Bull. Am. Meteorol. Soc. 87, 1523-1537. https://doi.org/10. 1175/BAMS-87-11-1523.

Shapiro, L.J., 1983. The asymmetric boundary layer flow under a translating hurricane. J. Atmos. Sci. 40 (8), 1984-1998.

Shchepetkin, A.F., McWilliams, J.C., 2005. The regional ocean modeling system: a splitexplicit free-surface, topography-following coordinates ocean model. Ocean Model 9, 347-404. https://doi.org/10.1016/jocemod.2004.08.002.

Shepherd, T.J., Walsh, K.J., 2017. Sensitivity of hurricane track to cumulus parameterization schemes in the WRF model for three intense tropical cyclones: impact of convective asymmetry. Meteorog. Atmos. Phys. 129 (4), 345-374.

Skamarock, W.C., Klemp, J.B., Dudhia, J., Gill, D.O., Barker, D.M., Duda, M.G., Huang, X. Y., Wang, W., Powers, J.G., 2008. A Description of the Advanced Research WRF Version 3. NCAR Technical Note, NCAR, Boulder, CO, USA.

Stark, J.D., Donlon, C.J., Martin, M.J., McCulloch, M.E., 2007. OSTIA: An Operational, High Resolution, Real Time, Global Sea Surface Temperature Analysis System., Oceans 07 IEEE Aberdeen, Conference Proceedings. Marine Challenges: Coastline to Deep Sea. Aberdeen, Scotland.IFFE. 
Strazzo, S., Elsner, J.B., Trepanier, J.C., Emanuel, K.A., 2013. Frequency, intensity, and sensitivity to sea surface temperature of North Atlantic tropical cyclones in best-track and simulated data. J. Adv. Model. Earth Syst. 5, 500-509. https://doi.org/10.1002/ jame.20036.

Tiedtke, M.A., 1989. Comprehensive mass flux scheme for cumulus parameterization in large-scale models. Mon. Weather Rev. 117, 1779-1800. https://doi.org/10.1175/ 1520-0493(1989) $117<1779$ :ACMFSF $>2.0$. CO;2.

Torn, R.D., Davis, D.A., 2012. The influence of shallow convection on tropical cyclone track forecasts. Mon. Weather Rev. 140, 2188-2197.

Troy, T.J., Wood, E.F., 2009. Comparison and validation of gridded radiation products across northern Eurasia. Environ. Res. Lett. 4 (045008), 7. https://doi.org/10.1088/ 1748-9326/4/4/045008.

Walsh, K., 2004. Tropical cyclones and climate change: unresolved issues. Clim. Res. 27 (1), 77-83.

Walsh, K.J., McBride, J.L., Klotzbach, P.J., Balachandran, S., Camargo, S.J., Holland, G., Sugi, M., 2016. Tropical cyclones and climate change. Wiley Interdiscip. Rev. Clim. Chang. 7 (1), 65-89. https://doi.org/10.1002/wcc.371.

Warner, J.C., Sherwood, C.R., Arango, H.G., Signell, R.P., 2005. Performance of four turbulence closure methods implemented using a generic length scale method. Ocean Model 8, 81-113.

Warner, J.C., Sherwood, C.R., Signell, R.P., Harris, C.K., Arango, H.G., 2008.
Development of a three-dimensional, regional, coupled wave, current, and sedimenttransport model. Comput. Geosci. 34, 1284-1306.

Warner, J.C., Armstrong, B., He, R., Zambon, J.B., 2010. Development of a coupled ocean-atmosphere-wave-sediment transport (COAWST) modeling system. Ocean Model 35 (3), 230-244.

Winterbottom, H.R., Ulhorn, E.W., Chassignet, E.P., 2012. A design and an application of a regional coupled atmosphere-ocean model for tropical prediction. J. Adv. Model. Earth Sys. 4 (M10002), 1-17. https://doi.org/10.1029/2012MS000172.

Yablonsky, R.M., Ginis, I., Thomas, B., Tallapragada, V., Sheinin, D., Bernardet, L., 2015. Description and analysis of the ocean component of NOAA's operational hurricane weather research and forecasting model (HWRF). J. Atmos. Ocean. Technol. 32 (1), 144-163. https://doi.org/10.1175/JTECH-D-14-00063.1.

Zambon, J., He, R., Warner, J.C., 2014. Investigation of hurricane Ivan using the coupled ocean-atmosphere-wave-sediment transport (COAWST) model. Ocean Dyn. 64, 1535-1554. https://doi.org/10.1007/s10236-014-0777-7.

Zhang, C., Wang, Y., Hamilton, K., 2011. Improved representation of boundary layer clouds over the southeast pacific in ARW-WRF using a modified Tiedtke cumulus parameterization scheme. Mon. Weather Rev. 139, 3489-3513.

Zhu, T., Zhang, D.-L., 2006. The impact of storm-induced SST cooling on hurricane intensity. Adv. Atmos. Sci. 23, 14-22. https://doi.org/10.1007/s00376-006-0002-9. 